\title{
Small-scale temporal and spatial variations in protistan community composition at the San Pedro Ocean Time-series station off the coast of southern California
}

\author{
Alle A. Y. Lie ${ }^{1, *}$, Diane Y. Kim ${ }^{1}$, Astrid Schnetzer ${ }^{2}$, David A. Caron ${ }^{1}$ \\ ${ }^{1}$ Department of Biological Sciences, University of Southern California, 3616 Trousdale Parkway, Los Angeles, \\ California 90089-0371, USA \\ ${ }^{2}$ Department of Marine, Earth and Atmospheric Sciences, North Carolina State University, 2800 Faucette Drive, 4148 Raleigh, \\ North Carolina 27695, USA
}

\begin{abstract}
Small-scale spatial and temporal variabiliy in protistan community composition was investigated at the USC San Pedro Ocean Time-series (SPOT) station and contrasted with a $10 \mathrm{yr}$ (2000 to 2010) dataset of samples collected at approximately monthly intervals from the same station. Surface seawater samples were collected for 12 consecutive days at the SPOT station, and an additional 17 stations (16 within a grid surrounding the SPOT station and 1 outlying station; 2 to $21 \mathrm{~km}$ apart) were sampled during 1 of the 12 sampling days, to investigate the small-scale temporal and spatial variability, respectively. Terminal restriction fragment length polymorphism (T-RFLP) analysis of the 18S rRNA gene was used to generate DNA fingerprints of the protistan community, which were used for the calculation of pair-wise Bray-Curtis and Jaccard similarity values at different spatial and temporal scales. Temperature, salinity, $\mathrm{pH}$, wind, and upwelling did not appear to have any significant effect on community composition, and distance had a weak correlation with the similarity indices generated from spatial samples. Communities separated by the smallest spatial scales ( 0 to $2 \mathrm{~km}$ ) had significantly higher average similarity than communities separated by small temporal scales ( 1 to $9 \mathrm{~d}$ ). Comparisons with a 10 yr dataset of monthly samples revealed significantly lower average similarity values among communities separated by time periods $\geq 1 \mathrm{mo}$ (45 to $52 \%$ ) compared to communities separated by the smallest spatial ( 0 to $2 \mathrm{~km} ; 67$ to $71 \%$ ) and temporal $(1 \mathrm{~d} ; 64 \%)$ scales. Our results indicate that small-scale spatial and day-to-day variability of protistan communities was overshadowed by monthly, seasonal, and interannual variabilities.
\end{abstract}

KEY WORDS: Protists - Microbial eukaryotes · Timeseries $\cdot$ Spatial variability $\cdot$ Temporal variability $\cdot$ T-RFLP

Resale or republication not permitted without written consent of the publisher

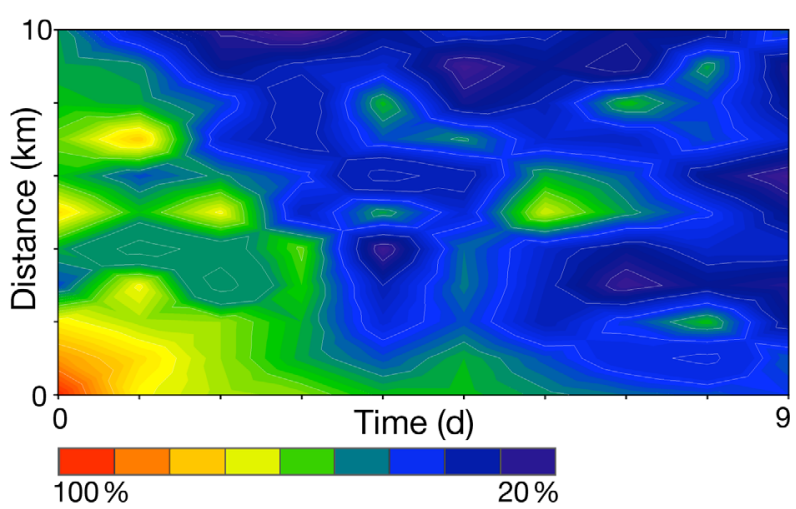

Conceptual spatial and temporal variability of protistan communities: a community collected at the San Pedro Ocean Time-series (SPOT) station on a specific day is compared to communities collected up to $10 \mathrm{~km}$ away within 9 days using the Bray-Curtis similarity index. Scale bar: pairwise community similarity

Photo: Alle Lie

\section{INTRODUCTION}

Microbial eukaryotes, primarily protists, are a diverse group of organisms with major ecological importance. Photosynthetic protists form the base of most aquatic food webs as primary producers, and heterotrophic species participate in nutrient remineralization and the transfer of energy to higher trophic levels through their role as consumers of bacteria and other protists (Sherr et al. 2007). More recently, the use of molecular methods for detecting protists in the environment has also revealed an 
increasing number of occurrences of protistan parasites that prey on both metazoans and other protists (Moreira \& López-García 2003, Guillou et al. 2008, Mangot et al. 2010). The emergent properties of protistan assemblages are intimately dependent on the taxonomic composition of the community. Changes in phytoplankton composition, for example, can affect the total primary productivity and food-web structure of the community (Côté \& Platt 1983, Takao et al. 2012), while changes in microzooplankton community composition can affect top-down grazing control of the phytoplankton community, resulting in blooms of specific phytoplankton taxa (Irigoien et al. 2005). A thorough understanding of the spatial and temporal dynamics of the protistan assemblage is necessary to predict community response to environmental perturbations and its impact on ecologically important rates (Menden-Deuer 2008).

Long-term time-series, such as the Bermuda Atlantic Time-series and Hawaii Ocean Time-series, have provided valuable data for understanding microbial community dynamics and biogeochemistry in oceanic ecosystems (Steinberg et al. 2001, Dore et al. 2008, Villareal et al. 2012). However, there are fewer long-term time-series of microbial dynamics from coastal zones. One is the San Pedro Ocean Timeseries (SPOT) station, where protistan communities have been collected since 2000 as a component of the University of Southern California (USC) Microbial Observatory project (2000 to 2012) and the Dimensions of Biodiversity program (2012 to present). This extensive collection of data has provided insights into the monthly-to-interannual changes in protistan community composition as well as the vertical structure of this assemblage (Countway et al. 2010, Schnetzer et al. 2011, Steele et al. 2011).

Protistan communities at the SPOT station have been collected at approximately monthly intervals to examine long-term changes in community composition, but monthly snapshots might not be sufficient for a thorough understanding of community dynamics. Maximal doubling times of most protists are on the order of hours to days (Hansen et al. 1997, Rose \& Caron 2007, Caron et al. 2012), allowing them to respond rapidly to changes in environmental conditions as well as to changes in their prey or predator abundances (Johansson et al. 2004, Landry \& Calbet 2004, Caron \& Countway 2009). Rapid changes in protistan communities have been demonstrated in field studies, where dramatic shifts in the community composition have been observed within weeks or even days (Countway et al. 2005, Xu et al. 2008, Vigil et al. 2009, Kim et al. 2011).
Another potentially important factor confounding our understanding of protistan community dynamics is our poor knowledge of the horizontal spatial heterogeneity of these assemblages. Several studies of the small-scale spatial variations in prokaryote assemblages in recent decades have demonstrated significant horizontal spatial variability in bacterioplankton composition at micro- (several millimeters to centimeters; Long \& Azam 2001, Seymour et al. 2005) and small-scales (several kilometers; Hewson et al. 2006). Studies of the small-scale spatial variability of protistan communities, however, have focused largely on vertical position in the water column (e.g. Bark 1981, Rines et al. 2002, Lopes et al. 2005, Behnke et al. 2006). Information on the smallscale horizontal variability of protistan community composition is rare.

The objective of the present study was to expand our knowledge of the small-scale spatial and temporal variability of protistan community composition at the SPOT station off southern California. Surface water samples were collected for 12 consecutive days at the SPOT station, and from an additional 17 stations on 1 of the 12 consecutive sampling days. Terminal restriction fragment length polymorphism (T-RFLP) was employed to characterize protistan community composition. Small-scale spatial (0 to $2 \mathrm{~km}$ ) variability was generally significantly lower than small-scale temporal ( 1 to $9 \mathrm{~d}$ ) variability. Comparison of the present dataset to a $10 \mathrm{yr}$ T-RFLP dataset collected at the SPOT station revealed that the average similarity values of communities separated by small spatial (0 to $2 \mathrm{~km}$ ) and temporal (1 d) scales were significantly higher than communities separated over longer time-scales (1 to $36 \mathrm{mo}$; D. Y. Kim et al. unpubl.), indicating that small-scale spatial and temporal variability in protistan community composition was minor compared to monthly, seasonal, and interannual variability.

\section{MATERIALS AND METHODS}

\section{Sample collection}

Samples for the study of small-scale temporal variability in protistan community composition were collected at the USC SPOT station in the San Pedro Channel off the coast of southern California $\left(33^{\circ} 33^{\prime} \mathrm{N}, 118^{\circ} 24^{\prime} \mathrm{W}\right.$; Fig. 1). Samples were collected from the surface $(0$ to $1 \mathrm{~m}$ ) during daytime (between 09:00 and 14:00 $h_{\text {; }}$ see Table 1) for 12 consecutive days (16 to 27 May 2011). Temperature, salinity, and 
$\mathrm{pH}$ were measured with a YSI 63 portable meter at the time of sample collection. Triplicate aliquots (200 $\mathrm{ml}$ ) of surface water were filtered onto GF/F filters (25 mm, Whatman) for chlorophyll analysis. Chlorophyll samples were extracted in $7 \mathrm{ml}$ of $100 \%$ acetone for $24 \mathrm{~h}$ and analyzed on a TD-700 fluorometer (Turner Designs) before and after acidification (Strickland \& Parsons 1972). Samples for DNA analysis were prefiltered through $80 \mu \mathrm{m}$ mesh by gravity to remove most metazoa, in accordance with other protistan DNA samples collected and processed from the SPOT station (Countway et al. 2010, Schnetzer et al. 2011, D. Y. Kim et al. unpubl.). Prefiltered water (2 l) was then filtered onto a GF/F filter $(47 \mathrm{~mm}$, Whatman) by vacuum filtration ( $<10 \mathrm{~mm} \mathrm{Hg}$ ). Lysis buffer (100 mM Tris [pH 8], $100 \mathrm{mM} \mathrm{NaCl}, 1 \%$ SDS; $2 \mathrm{ml}$ ) was added to the filters, which were then stored at $-80^{\circ} \mathrm{C}$ until further processing.

Samples for the study of small-scale spatial variability in protistan community composition were collected at 17 stations surrounding and including the SPOT station on 25 May (Fig. 1; see Table 2 for coordinates). Adjacent stations differed by 1 longitudinal and/or latitudinal second, and the distance between stations was rounded to the nearest kilometer (i.e. 2 to $14 \mathrm{~km}$ apart). Stations in the inner sampling grid (i.e. S4, S5, S6, S9, SPOT, S11, S12,

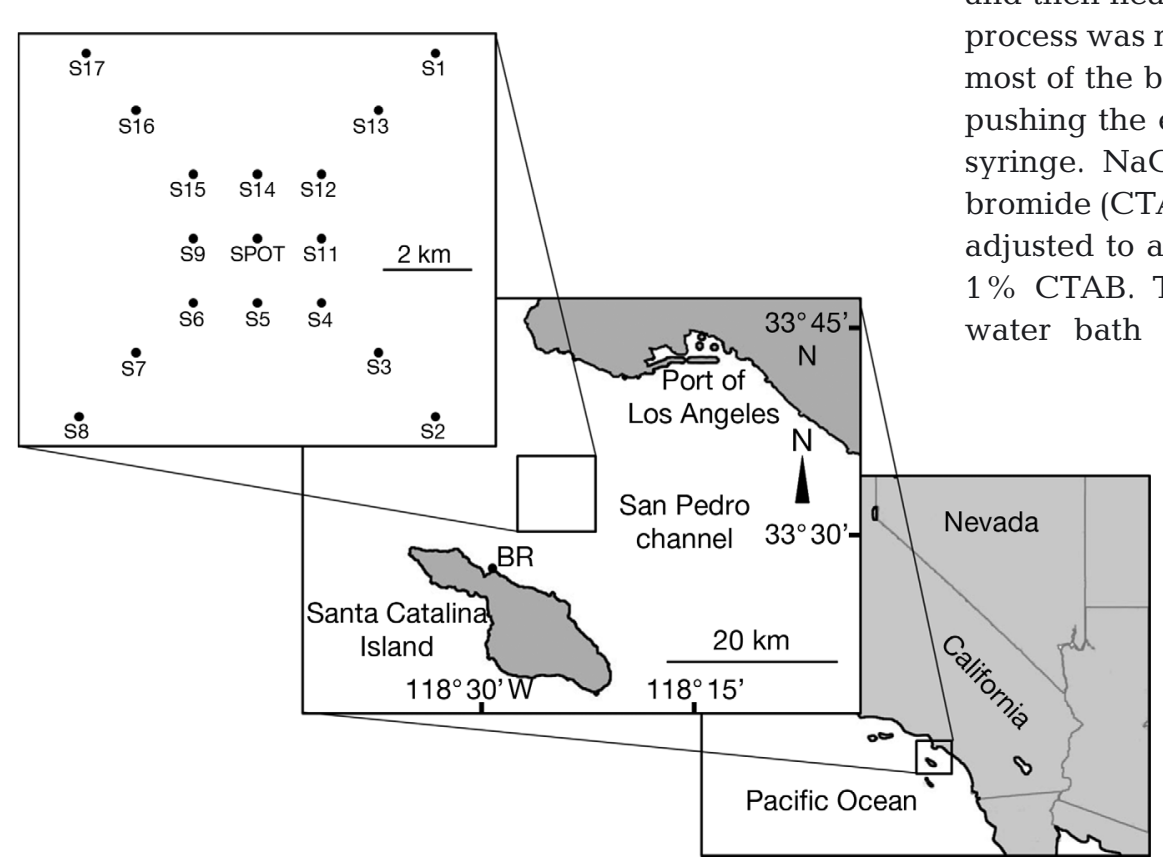

Fig. 1. Coastal southern California and 17 sampling stations at and around the San Pedro Ocean Time-series (SPOT) station. The outlying station near the small island Bird Rock (BR) is located off the eastern coast of Santa Catalina Island
S14, and S15) were, therefore, $2 \mathrm{~km}$ from each other. An outlying sampling station near a small island called Bird Rock (BR), located $\sim 200 \mathrm{~m}$ from Santa Catalina Island and $14 \mathrm{~km}$ away from the SPOT station, was also sampled on the same day. Analyses of the data did not include the sample from the BR station unless specified because it was only employed as an outlier for comparison among the 17 closely spaced stations at and surrounding the SPOT station. Three true replicate samples (S10A, S10B, and S10C) were collected at the SPOT station within minutes of each other on 25 May to characterize variability in community composition resulting from replicated sampling and sample processing. Sample S10A was used as the 25 May sample in the analysis of day-to-day temporal variability. Sampling procedures for samples used to examine small-scale spatial variability were the same as described above, except that chlorophyll samples were collected in duplicate instead of triplicate.

\section{DNA extraction and amplification}

DNA extraction and amplification procedures were done with slight modifications to those of Countway et al. (2005). Sample filters were first beaten with $200 \mu \mathrm{l}$ of $0.5 \mathrm{~mm}$ zircon beads on a vortex for $1 \mathrm{~min}$ and then heated in a $70^{\circ} \mathrm{C}$ water bath for $5 \mathrm{~min}$. The pushing the entire sample contents through a $10 \mathrm{ml}$ syringe. $\mathrm{NaCl}$ and hexadecyl-trimethyl-ammonium bromide (CTAB; Sigma) were added to the lysate and . The mixture was incubated in a $70^{\circ} \mathrm{C}$ or $10 \mathrm{~min}$ and then extracted and washed with phenol-chloroformisoamyl alcohol (25:24:1) and chloroform-isoamyl alcohol (24:1). A $2 \times$ volume of $95 \%$ ethanol and $0.1 \times$ volume of $10.5 \mathrm{M}$ ammonium acetate were added to the extract, and precipitation was allowed to take place overnight. The samples were then centrifuged for $30 \mathrm{~min}$ at $20800 \times g$, washed with $70 \%$ ethanol, and then centrifuged again for $15 \mathrm{~min}$ at $20800 \times g$. The pellet was air-dried and resuspended in TE buffer (10 mM Tris, 1 mM EDTA; pH 7.5) and stored at $-20^{\circ} \mathrm{C}$ until further processing. 
Fragments of $\sim 600 \mathrm{bp}$ were amplified using the primers D4-Euk-A (5'-D4-AAC CTG GTT GAT CCT GCC AGT-3') and Euk-570R (5'-GCT ATT GGA GCT GGA ATT AC-3') (Medlin et al. 1988, Countway et al. 2005). The 'D4' fluorescent dye on the forward primer D4-Euk-A was used to label the fragment for T-RFLP analysis. PCR reagents (50 $\mu \mathrm{l})$ were mixed at the following concentrations: $0.5 \mu \mathrm{M}$ of each primer, 1 PCR colorless buffer (Promega), $2.5 \mathrm{mM}$ of $\mathrm{MgCl}_{2}$ (Promega), $250 \mu \mathrm{M}$ of dNTPs (Promega), $300 \mathrm{ng} \mathrm{ul}^{-1}$ of BSA (Sigma-Aldrich), $2.5 \mathrm{U}$ of Taq (Promega), and $10 \mathrm{ng}$ of sample DNA. The thermal protocol of the PCR reaction was 1 cycle at $95^{\circ} \mathrm{C}$ for $2 \mathrm{~min}$ and 35 cycles at $95^{\circ} \mathrm{C}$ for $30 \mathrm{~s}$, followed by $30 \mathrm{~s}$ at $55^{\circ} \mathrm{C}$, and then $60 \mathrm{~s}$ at $72^{\circ} \mathrm{C}$. The reaction ended with a final extension at $72^{\circ} \mathrm{C}$ for $5 \mathrm{~min}$. Triplicate reactions were performed for each sample, and the resulting amplicons were pooled together for subsequent analysis.

\section{T-RFLP analysis}

T-RFLP analysis was performed according to Countway et al. (2005). The amplified samples were purified and concentrated into $50 \mu \mathrm{l}$ using a PCR purification kit (Qiagen) and then digested with $10 \mathrm{U}$ of mung bean nuclease (New England Biolabs) at $30^{\circ} \mathrm{C}$ for $1 \mathrm{~h}$ to remove single-stranded PCR products (Egert \& Friedrich 2003). The digested samples were purified again (Qiagen PCR purification kit) and quantified using a Qubit 2.0 fluorometer (Life technologies). The restriction enzymes, HaeIII and MnlI (10 U; New England Biolabs), were used separately to digest $300 \mathrm{ng}$ of the purified samples for $15 \mathrm{~h}$ at $37^{\circ} \mathrm{C}$. The digested fragments were precipitated using $1 \mu \mathrm{l}$ of $20 \mathrm{mg} \mathrm{ml}^{-1}$ glycogen (Roche), $2 \mu \mathrm{l}$ of $3 \mathrm{M}$ sodium acetate (Sigma), and $2 \times$ ice-cold $95 \%$ ethanol. Samples were then centrifuged at $5700 \times g$ and $4^{\circ} \mathrm{C}$ for $20 \mathrm{~min}$. The supernatant was removed, and the pellets were washed with $100 \mu \mathrm{l}$ of $70 \%$ ice-cold ethanol and centrifuged at $5700 \times g$ and $4^{\circ} \mathrm{C}$ again for $10 \mathrm{~min}$. This washing process was repeated one more time before the pellets were air dried for $20 \mathrm{~min}$. The pellets were then resuspended in $40 \mu$ of deionized formamide (Beckman-Coulter). Aliquots (5 to $10 \mu \mathrm{l}$ ) of the samples were further diluted with deionized formamide, and $0.5 \mu \mathrm{l}$ of 600 bp DNA size standard (Beckman-Coulter) was added to make up a final volume of $40 \mu \mathrm{l}$. Samples were run on a CEQ8000 capillary gel-electrophoresis DNA sequencer (Beckman-Coulter), and the TRFLP patterns were analyzed using the Fragment
Analysis module of the CEQ8000 Genetic Analysis software (Beckman-Coulter) as described by Countway et al. (2005). The total peak area of the fragments for each sample was normalized to the same value to allow comparisons between samples. Each unique fragment length was considered to be an operational taxonomic unit (OTU) based on the assumption that DNA from different species will yield DNA fragments of varying sizes when they are digested with restriction enzymes (Díez et al. 2001b).

\section{Assignment of putative identifications to T-RFLP fragments}

Full-length 18S rRNA gene sequences from Kim et al. (2012) were used to assign putative identifications (IDs) to the fragments generated by T-RFLP analysis in the present study. The full-length 18S rRNA gene sequences originated from a sample collected from $5 \mathrm{~m}$ at the SPOT station in October 2001. Sample processing and analyses are described by Kim et al. (2012). Briefly, 663 18S rRNA gene sequences were grouped into OTUs using the Microbial Eukaryote Species Assignment program (MESA) at 95\% sequence similarity (Caron et al. 2009), and each of these OTUs was assigned a taxonomic identification based on the best BLAST+ match to the SILVA (v108) database. The sequences were also subjected to in silico HaeIII restriction digestion that resulted in 98 fragments with unique sizes. These reference fragments were compared to the fragments generated in the present study to provide taxonomies for some of the latter fragments.

\section{Data analysis}

The software package PRIMER (v6) was used to analyze the community fingerprints resulting from the T-RFLP procedure (Clarke \& Warwick 2001). Normalized peak area values from the T-RFLP analysis were square-root transformed and then used to generate a matrix of pair-wise Bray-Curtis (BC) and Jaccard similarity values. The BC similarity value is an estimation of the percent similarity between a pair of communities based on the composition and relative abundances of OTUs, while the Jaccard similarity value estimates percent similarity between 2 communities based on the presence/absence of OTUs alone. The similarity values were used as inputs for both CLUSTER (using the 
group average mode and the SIMPROF test for significance) and nonmetric multidimensional scaling (nMDS) analyses for further analysis of the community composition variability. The group-average similarity values for clusters that were significantly different (SIMPROF; $\mathrm{p}<0.05$ ) in the CLUSTER analysis were overlaid on the nMDS plot to integrate the results of both analyses.

Daily variability in protistan community composition in relation to changes in environmental parameters was examined by both Spearman's correlation and BIO-ENV analysis (PRIMER v6). The environmental parameters included temperature, salinity, and $\mathrm{pH}$ as well as chlorophyll concentration. Additional daily hydrological data, including sea surface temperature (SST), wind direction, wind speed, and upwelling index, were obtained from online public databases and included in the analyses. All additional hydrological data were obtained from the National Oceanic and Atmospheric Administration (NOAA) CoastWatch database for the West Coast Regional Node (http://coastwatch.pfel.noaa.gov/), except for the upwelling index that was obtained from the NOAA Pacific Fisheries Environmental Laboratory website (www.pfeg.noaa.gov/products/ PFEL/modeled/indices/upwelling/NA/data_download. $\mathrm{html})$, for a station close to the SPOT station $\left(33^{\circ} \mathrm{N}\right.$, $119^{\circ} \mathrm{W}$ ) from 16 to 27 May 2011 (Table 1). Correlation between the pair-wise community composition similarity values for adjacent days was tested against the differences in each environmental parameter between the adjacent days using Spearman's correlation analysis. These environmental parameters were also used in a BIO-ENV analysis that examined which parameter, or combination of them, best correlated with the variability observed among the communities in the daily samples.

Spatial variability in relation to environmental parameters was also investigated using BIO-ENV. The relationship between spatial variability and physical distance between stations was investigated through the RELATE analysis in PRIMER (v6). Contour maps were plotted in SigmaPlot (v11), with values between stations generated through linear interpolation.

The average similarity values of communities separated by different distances or time periods were compared using a multiple comparison procedure. Community similarity values were divided into groups depending on the distance (spatial samples) or time (temporal samples) between collections. Comparisons of the average similarity values of each group were then made using Dunnett's multiple comparison test (20\% trimmed average) through the R statistical software (Wilcox 2012). Groups with few observations (i.e. $\mathrm{n}<3$; communities separated by $11 \mathrm{~km}, 14 \mathrm{~km}$, and $>9$ d) were not included in the comparisons and figures. Emphasis was placed on comparisons among groups with the smallest spatial or temporal scales (i.e. communities separated by $0 \mathrm{~km}$ [replicates], $2 \mathrm{~km}$, and $1 \mathrm{~d}$ ), and only the BC similarity index was used for comparisons as it is a more holistic estimate (i.e. abundance-based) of community similarity.

\section{Comparison with a $10 \mathrm{yr}$ T-RFLP dataset collected at the SPOT station}

A long-term time-series of T-RFLP data collected at approximately monthly intervals from the SPOT station (2000 to 2010; D. Y. Kim et al. unpubl.) was used to compare the small-scale spatial and temporal variability investigated in the present study to community variability over longer time scales. Collection of the long-term time-series samples began in September 2000, with occasional gaps of up to several months and a hiatus from September 2006 to March 2008. Samples were collected from a depth of $5 \mathrm{~m}$ using 101 Niskin bottles (General Oceanics) mounted to a CTD rosette and processed and analyzed as described in the present study.

\section{RESULTS}

\section{Environmental parameters}

Average ( \pm 1 standard deviation) temperature, salinity, $\mathrm{pH}$, and chlorophyll a concentration during the $12 \mathrm{~d}$ of the small-scale temporal variability study were $17.0^{\circ} \mathrm{C} \quad\left( \pm 0.1^{\circ} \mathrm{C}\right), \quad 33.2( \pm 0.2), 8.13$ $( \pm 0.09)$, and $0.74 \mu \mathrm{g} \mathrm{l}^{-1}\left( \pm 0.23 \mu \mathrm{g} \mathrm{l}^{-1}\right)$, respectively (Table 1). Average $( \pm 1 \mathrm{SD})$ temperature, salinity, $\mathrm{pH}$, and chlorophyll a concentration among the 17 closely spaced stations surrounding and including the SPOT station on 25 May were $17.6^{\circ} \mathrm{C}\left( \pm 0.5^{\circ} \mathrm{C}\right)$, $33.4( \pm 0.2), 8.18( \pm 0.03)$, and $0.72 \mu \mathrm{g} \mathrm{l}^{-1}( \pm 0.34 \mu \mathrm{g}$ $\left.\mathrm{l}^{-1}\right)$, respectively (Table 2 ). The temperature, salinity, and $\mathrm{pH}$ at the outlying station $\mathrm{BR}$ were within the range of those measured at the 17 closely spaced stations, but the chlorophyll a concentration at the BR station was $1.86 \mu \mathrm{g} \mathrm{l}^{-1}$, 1.5 -fold higher than the highest chlorophyll a concentration measured among the 17 closely spaced stations $(1.12 \mu \mathrm{g}$ $1^{-1}$ at Stn S6). 
Table 1. Date, time of day, physical and chemical parameters, and chlorophyll a (chl a) concentrations at the time of collection of the samples used to examine small-scale temporal variability in protistan community composition. Additional hydrological data were downloaded from the NOAA CoastWatch database for the West Coast Regional Node (http://coastwatch.pfel.noaa. gov/) and the NOAA Pacific Fisheries Environmental Laboratory website (www.pfeg.noaa.gov/products/PFEL/modeled/ indices/upwelling/NA/data_download.html) for a station located at $33^{\circ} \mathrm{N}, 119^{\circ} \mathrm{W}$. SST: sea surface temperature. The upwelling index is calculated based on the pressure generated by upwelling water mass. A positive value indicates an upward displacement of water

\begin{tabular}{|c|c|c|c|c|c|c|c|c|c|}
\hline $\begin{array}{l}\text { Date } \\
(2011)\end{array}$ & $\begin{array}{c}\text { Time of } \\
\text { day }\end{array}$ & $\begin{array}{c}\text { Temperature } \\
\left({ }^{\circ} \mathrm{C}\right)\end{array}$ & Salinity & $\mathrm{pH}$ & $\begin{array}{c}\mathrm{Chl} \text { a }\left(\mu g \mathrm{l}^{-1} ;\right. \\
\text { mean } \pm \mathrm{SD})\end{array}$ & $\begin{array}{l}\mathrm{SST} \\
\left({ }^{\circ} \mathrm{C}\right)\end{array}$ & $\begin{array}{c}\text { Wind direction } \\
\left({ }^{\circ} \text { true }\right)\end{array}$ & $\begin{array}{l}\text { Wind speed } \\
\qquad\left(\mathrm{m} \mathrm{s}^{-1}\right)\end{array}$ & $\begin{array}{l}\text { Upwelling } \\
\text { index }\end{array}$ \\
\hline 16 May & $09: 45$ & 16.9 & 32.8 & 8.01 & $0.72 \pm 0.07$ & 16.3 & 229.2 & 4.9 & 86 \\
\hline 17 May & $08: 37$ & 16.4 & 33.4 & 8.23 & $0.61 \pm 0.06$ & 16.2 & 229.2 & 4.5 & 71 \\
\hline 18 May & $08: 37$ & 16.6 & 33.3 & 8.22 & $0.70 \pm 0.14$ & 16.2 & 228.5 & 4.4 & 187 \\
\hline 19 May & $08: 22$ & 15.8 & 33.3 & 8.09 & $1.08 \pm 0.13$ & 16.2 & 230.4 & 4.3 & 140 \\
\hline 20 May & 09:05 & 16.9 & 32.8 & 8.07 & $0.71 \pm 0.04$ & 16.2 & 232.8 & 4.5 & 138 \\
\hline 21 May & $10: 25$ & 16.4 & 33.1 & 8.17 & $0.73 \pm 0.06$ & 16.1 & 235.2 & 4.8 & 177 \\
\hline 22 May & $13: 28$ & 18.7 & 33.1 & 8.19 & $1.12 \pm 0.10$ & 16.0 & 238.0 & 5.0 & 264 \\
\hline 23 May & $08: 27$ & 16.0 & 33.4 & 8.19 & $0.86 \pm 0.07$ & 15.9 & 239.1 & 5.4 & 272 \\
\hline 24 May & 09:12 & 16.2 & 33.2 & 8.14 & $0.93 \pm 0.04$ & 15.7 & 240.2 & 5.3 & 178 \\
\hline 25 May & $11: 50$ & 17.9 & 33.6 & 8.17 & $0.63 \pm 0.10$ & 15.7 & 241.9 & 5.2 & 211 \\
\hline 26 May & $10: 14$ & 17.2 & 33.3 & 7.95 & $0.47 \pm 0.04$ & 15.7 & 245.7 & 5.2 & 293 \\
\hline 27 May & $13: 10$ & 18.8 & 33.4 & 8.18 & $0.36 \pm 0.03$ & 15.6 & 247.5 & 5.2 & 328 \\
\hline
\end{tabular}

\section{T-RFLP analysis of the protistan community composition}

The results generated from the 2 restriction enzymes employed in the T-RFLP analysis, HaeIII and $M n l I$, led to similar conclusions. Only results from the HaeIII analyses are presented since HaeIII generated, on average, more fragments per sample (39) than

Table 2. Station coordinates, physical and chemical parameters, and chlorophyll a concentrations at the time of collection of the samples used to examine small-scale spatial variability in protistan community composition on 25 May 2011 (see Fig. 1 for station abbreviations)

\begin{tabular}{|c|c|c|c|c|c|}
\hline Stn & Coordinates & $\begin{array}{c}\text { Temperature } \\
\left({ }^{\circ} \mathrm{C}\right)\end{array}$ & Salinity & $\mathrm{pH}$ & $\begin{array}{c}\text { Chlorophyll a } \\
\left(\mu \mathrm{g} \mathrm{l}^{-1}\right) ; \text { mean } \pm \mathrm{SD}\end{array}$ \\
\hline $\mathrm{S} 1$ & $33^{\circ} 36^{\prime} \mathrm{N}, 118^{\circ} 21^{\prime} \mathrm{W}$ & 17.4 & 33.3 & 8.23 & $0.33 \pm 0.04$ \\
\hline $\mathrm{S} 2$ & $33^{\circ} 30^{\prime} \mathrm{N}, 118^{\circ} 21^{\prime} \mathrm{W}$ & 18.4 & 33.5 & 8.19 & $0.48 \pm 0.03$ \\
\hline S3 & $33^{\circ} 31^{\prime} \mathrm{N}, 118^{\circ} 22^{\prime} \mathrm{W}$ & 18.2 & 33.4 & 8.21 & $0.48 \pm 0.01$ \\
\hline $\mathrm{S} 4$ & $33^{\circ} 32^{\prime} \mathrm{N}, 118^{\circ} 23^{\prime} \mathrm{W}$ & 18.0 & 33.5 & 8.18 & $0.62 \pm 0.11$ \\
\hline S5 & $33^{\circ} 32^{\prime} \mathrm{N}, 118^{\circ} 24^{\prime} \mathrm{W}$ & 17.3 & 33.7 & 8.22 & $0.82 \pm 0.03$ \\
\hline S6 & $33^{\circ} 32^{\prime} \mathrm{N}, 118^{\circ} 25^{\prime} \mathrm{W}$ & 17.6 & 33.4 & 8.17 & $0.92 \pm 0.30$ \\
\hline $\mathrm{S} 7$ & $33^{\circ} 31^{\prime} \mathrm{N}, 118^{\circ} 26^{\prime} \mathrm{W}$ & 17.2 & 33.2 & 8.15 & $0.84 \pm 0.04$ \\
\hline S8 & $33^{\circ} 30^{\prime} \mathrm{N}, 118^{\circ} 27^{\prime} \mathrm{W}$ & 17.3 & 33.4 & 8.12 & $1.12 \pm 0.16$ \\
\hline S9 & $33^{\circ} 33^{\prime} \mathrm{N}, 118^{\circ} 25^{\prime} \mathrm{W}$ & 17.2 & 33.7 & 8.15 & $0.81 \pm 0.15$ \\
\hline SPOT & $33^{\circ} 33^{\prime} \mathrm{N}, 118^{\circ} 24^{\prime} \mathrm{W}$ & 17.9 & 33.6 & 8.17 & $0.63 \pm 0.10$ \\
\hline S11 & $33^{\circ} 33^{\prime} \mathrm{N}, 118^{\circ} 23^{\prime} \mathrm{W}$ & 17.3 & 33.4 & 8.20 & $0.47 \pm 0.12$ \\
\hline S12 & $33^{\circ} 34^{\prime} \mathrm{N}, 118^{\circ} 23^{\prime} \mathrm{W}$ & 17.4 & 33.0 & 8.21 & $0.40 \pm 0.00$ \\
\hline S13 & $33^{\circ} 35^{\prime} \mathrm{N}, 118^{\circ} 22^{\prime} \mathrm{W}$ & 16.7 & 33.4 & 8.23 & $0.36 \pm 0.02$ \\
\hline S14 & $33^{\circ} 34^{\prime} \mathrm{N}, 118^{\circ} 24^{\prime} \mathrm{W}$ & 18.4 & 33.6 & 8.17 & $0.65 \pm 0.18$ \\
\hline S15 & $33^{\circ} 34^{\prime} \mathrm{N}, 118^{\circ} 25^{\prime} \mathrm{W}$ & 17.2 & 33.2 & 8.16 & $1.03 \pm 0.41$ \\
\hline S16 & $33^{\circ} 35^{\prime} \mathrm{N}, 118^{\circ} 26^{\prime} \mathrm{W}$ & 17.6 & 33.3 & 8.14 & $0.71 \pm 0.29$ \\
\hline S17 & $33^{\circ} 36^{\prime} \mathrm{N}, 118^{\circ} 27^{\prime} \mathrm{W}$ & 17.6 & 33.5 & 8.19 & $0.65 \pm 0.08$ \\
\hline $\mathrm{BR}$ & $33^{\circ} 27^{\prime} \mathrm{N}, 118^{\circ} 29^{\prime} \mathrm{W}$ & 17.6 & 33.6 & 8.12 & $1.86 \pm 0.86$ \\
\hline
\end{tabular}

Values corrected after publication
MnlI (37), which provided a greater resolution of the species composition for subsequent analysis.

A total of 118 fragments with unique sizes (i.e. OTUs) were generated from all samples $(\mathrm{n}=32)$. Samples used to examine small-scale spatial variability in protistan community composition $(n=20)$ generated 103 OTUs, 23 of which occurred only once in the 17 stations at or around the SPOT station. There were 2 OTUs that were found only in the sample collected at the outlying station BR. The samples used to examine small-scale temporal (daily) variability $(\mathrm{n}=12)$ generated 106 OTUs, 23 of which were found only on a single sampling date. There were 5 OTUs that were found only in the spatial samples and 8 OTUs that were found only in the daily samples.

Commonly occurring OTUs, defined as OTUs that were present in more than half of the samples of each dataset (i.e. spatial and daily samples), were compared with reference fragments generated through in silico digestion of full-length 18S rRNA gene sequences from Kim et al. (2012) for the assignment of putative IDs. Putative IDs were assigned to 19 of 27 commonly occurring OTUs found in the spatial sam- 
ples (Table S1 in the Supplement at www.int-res. com/articles/suppl/a070p093_supp.pdf) and 20 of 27 commonly occurring OTUs found in the daily samples (Table S2 in the Supplement). There were 21 of these commonly occurring OTUs that were common to both the spatial and daily samples, and 16 of them had matches with the reference fragments (Tables S1 \& S2 in the Supplement).
The spatial distributions of commonly occurring OTUs were patchy, but their relative abundances were often correlated (Fig. 2). There were 50 significant correlations in the relative abundance of commonly occurring OTUs with putative IDs found among the spatial samples, with 24 positives and 26 negatives (Spearman's correlation, p <0.05; Fig. S2A in the Supplement). Examples of putative IDs of 4 commonly

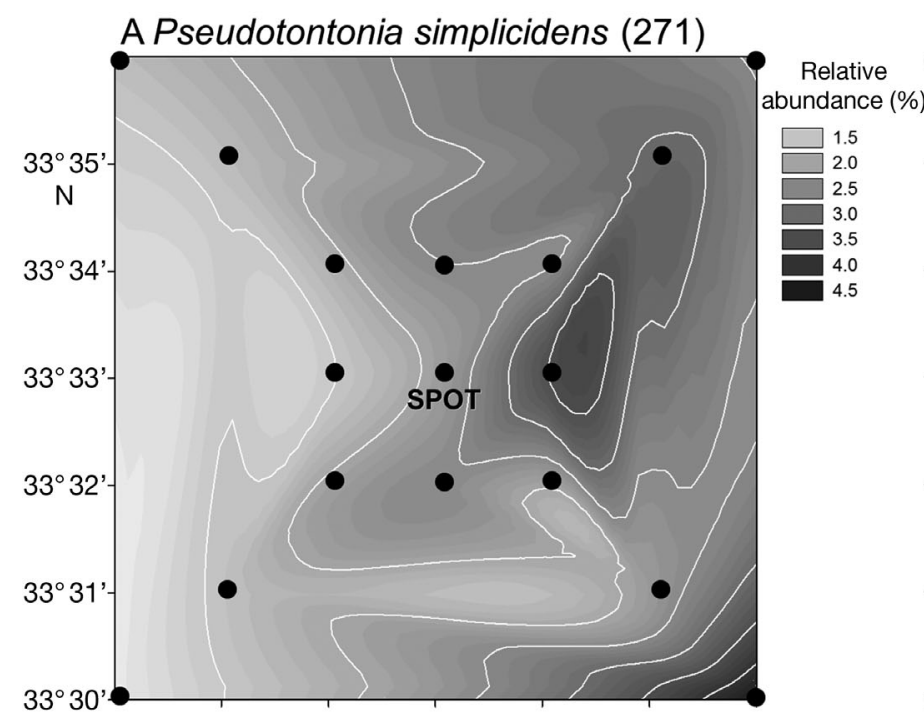

B Phaeocystis cordata (274)

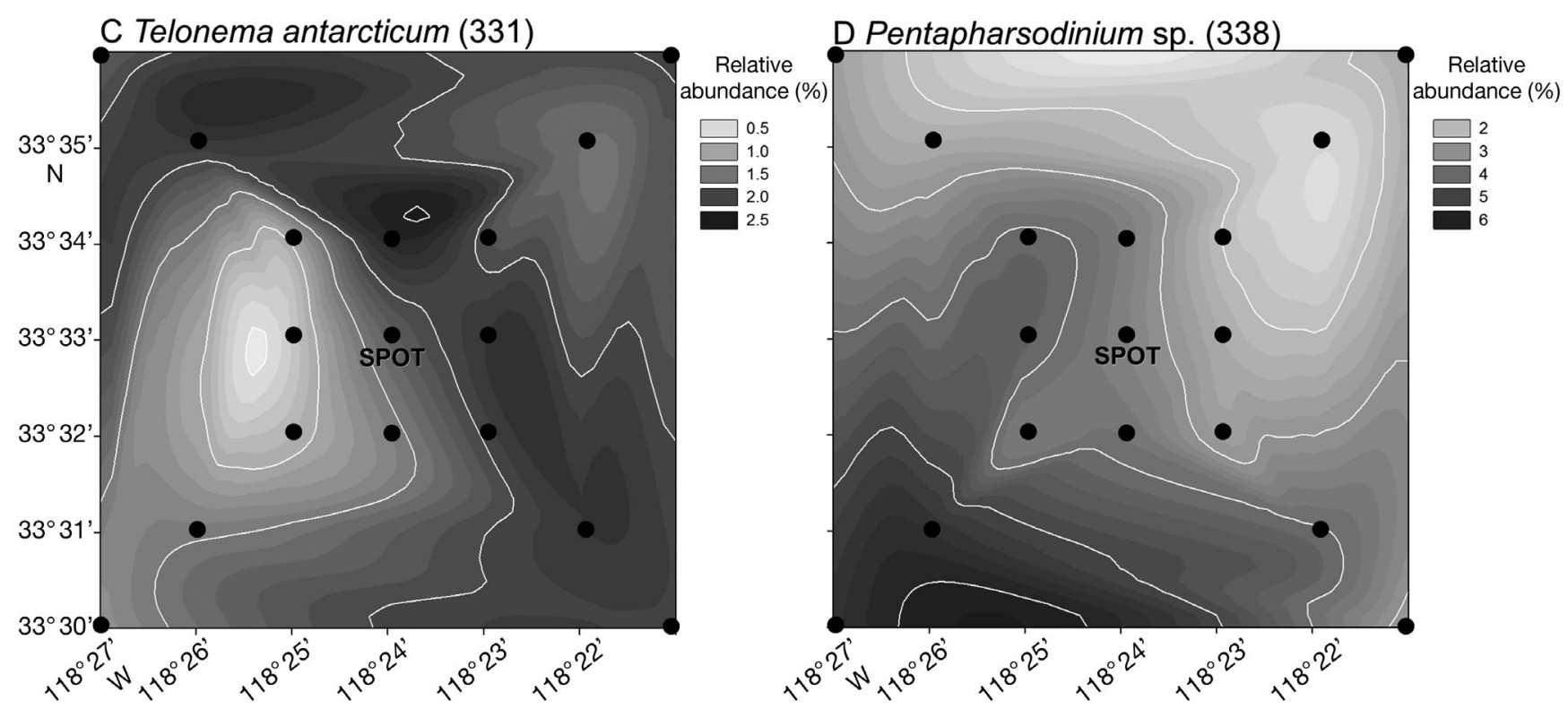

Fig. 2. Contour maps of the relative abundances of 4 commonly occurring OTUs among samples used to examine small-scale spatial variability in protistan community composition at 17 stations surrounding and including the SPOT station. Black dots indicate station positions (see Fig. 1 for station identities). Contour lines have been drawn at the border between the relative abundances shown in the legend. Relative abundances at the SPOT station were the average of the 3 true replicate samples (S10A, S10B, and S10C). Putative IDs assigned to these commonly occurring OTUs, based on the fragment sizes predicted from an in silico T-RFLP analysis of a full-length 18S sequence database from the same locale and the best BLAST+ matches for those sequences (Kim et al. 2012; see 'Materials and methods'), were (A) the ciliate Pseudotontonia simplicidens, (B) the haptophyte Phaeocystis cordata, (C) the telonemid Telonema antarcticum, and (D) the dinoflagellate Pentapharsodinium sp.

The numbers in brackets next to the putative IDs indicate the fragment sizes of the OTUs 
occurring OTUs with correlations in their relative abundance (Spearman's correlation, $\mathrm{p}<0.05$ ) include the ciliate Pseudotontonia simplicidens (Fig. 2A), the haptophyte Phaeocystis cordata (Fig. 2B), the telonemid Telonema antarcticum (Fig. 2C), and the dinoflagellate Pentapharsodinium sp. (Fig. 2D). There were significant positive correlations between the relative abundances of $P$. simplicidens and $T$. antarcticum (Fig. 2A,C), and between the relative abundances of
P. cordata and Pentapharsodinium (Fig. 2B,D). The relative abundances of $P$. simplicidens and T. antarcticum were significantly and negatively correlated to the relative abundances of $P$. cordata and Pentapharsodinium. The relative abundances of commonly occurring OTUs (with putative IDs) in daily samples had a lower number of significant correlations, with 14 positives and 13 negatives (Spearman's correlation; $\mathrm{p}<0.05$, Fig. S2B).
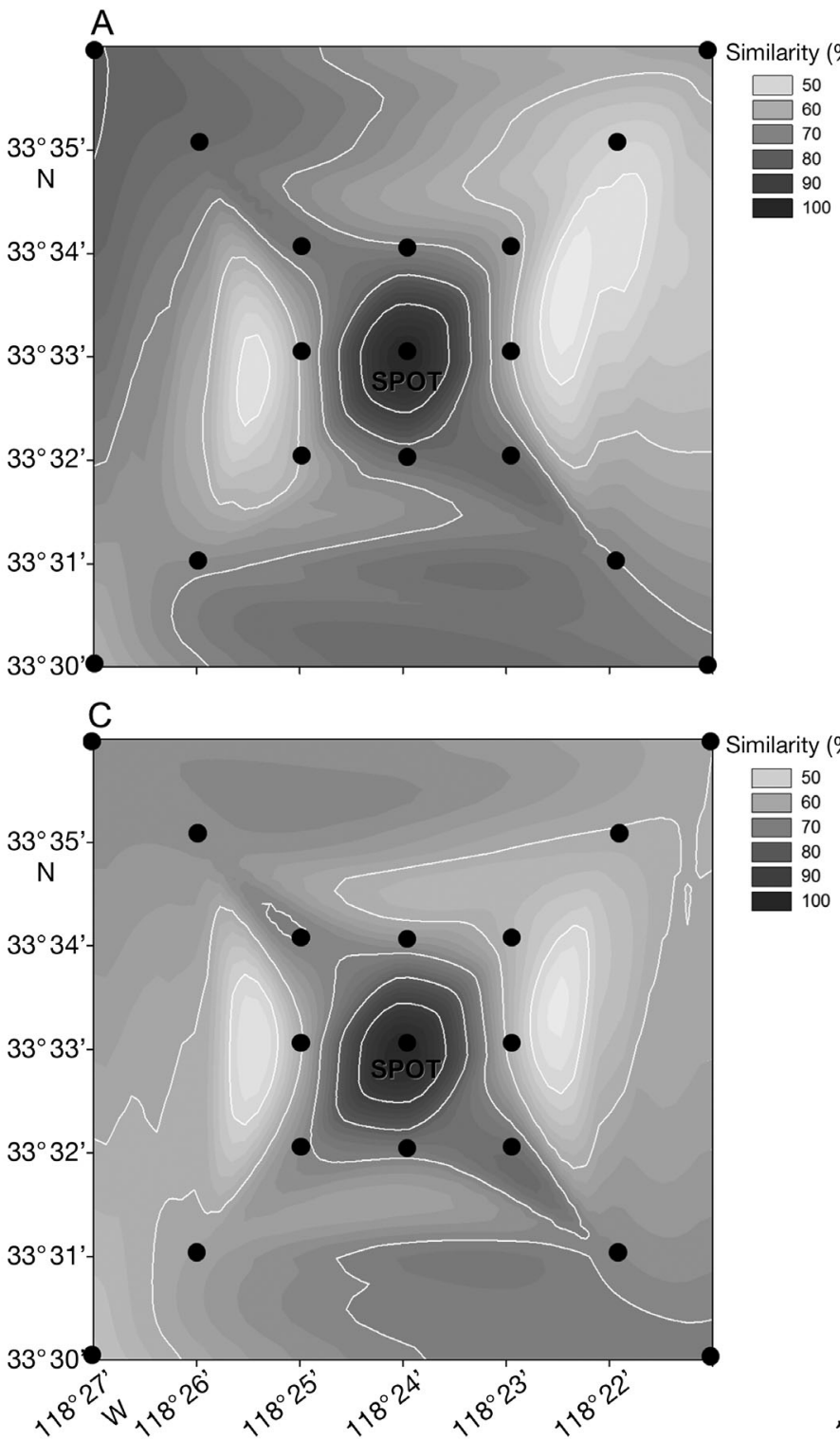
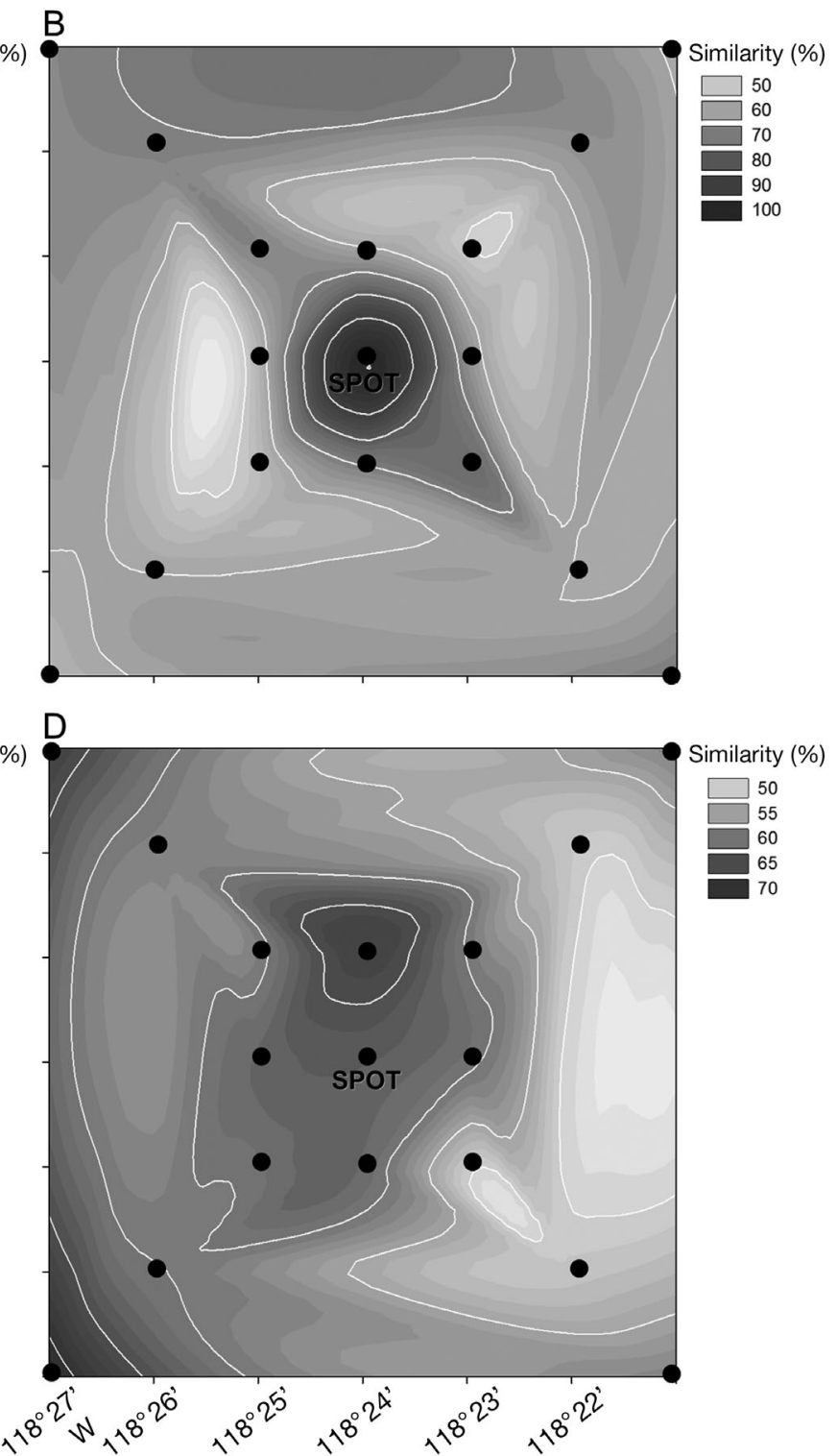

Fig. 3. Contour maps of the pair-wise Bray-Curtis similarity values of protistan communities collected at 17 stations surrounding and including the SPOT station compared to the 3 true replicate samples collected at the SPOT station - (A) S10A, (B) S10B, and (C) S10C-and (D) the outlying station, BR. Black dots indicate station positions (see Fig. 1 for station identities). Contour lines have been drawn at the border between the similarity values shown in the legend. The samples S10A, S10B, and S10C were anchors and compared against themselves in A-C, making the community composition similarity at the SPOT station $100 \%$. The community from sample S10A was used as the representative community for the SPOT station and compared against the anchor community from BR in D. Stn BR is not present on the contour map 


\section{Similarity of protistan communities over small spatial and temporal scales}

The 2 similarity indices, BC and Jaccard, generated similar patterns, although the Jaccard similarity values were lower than the corresponding $\mathrm{BC}$ values. $\mathrm{BC}$ similarity values estimated for all samples (spatial and daily) averaged $59 \%(\mathrm{n}=435 ; 37$ to $80 \%)$. The average similarity value for the spatial samples was $63 \%(\mathrm{n}=171 ; 37$ to $80 \%)$, while the average for the daily samples was $58 \%(n=66 ; 37$ to $78 \%)$. The average Jaccard similarity values for all samples, spatial samples alone, and daily samples alone were $43 \%$ ( $\mathrm{n}=435 ; 21$ to $69 \%), 48 \%(\mathrm{n}=171 ; 23$ to $69 \%)$, and $42 \%(\mathrm{n}=66 ; 21$ to $62 \%)$, respectively. Comparison of the 17 stations to the outlying station, BR, generated average similarity values of $60 \%$ and $44 \%(n=17)$ for the BC (Fig. 3D) and Jaccard indices, respectively.

Physical and chemical environmental parameters were not related to small-scale spatial and temporal variability for either of the similarity indices. Spearman's correlation did not reveal any significant correlations between community similarity and changes in all environmental parameters (data from the present study and additional hydrological data from NOAA) between adjacent days ( $p>0.05$ ). BIO-ENV analysis also did not reveal any significant correlations between the environmental parameters and daily variability $(p>0.05)$. All physical and chemical environmental parameters were uncorrelated with spatial variability as well (BIO-ENV; $\mathrm{p}>0.05$ ). Only chlorophyll concentration, a biological parameter, yielded significant correlations with spatial variability (BIO-ENV; BC: $\rho=0.657, p=0.001$; Jaccard: $\rho=$ $0.604, p=0.001$; Fig. S1 in the Supplement).

Contour maps plotted using BC similarity values of spatial samples revealed variations in protistan community composition over a few kilometers (Fig. 3). Similar patterns were observed when communities collected from the 16 closely spaced stations in the vicinity of the SPOT station were compared to each of the 3 replicates collected at the SPOT station (Fig. 3A-C). Small patches with community compositions relatively dissimilar from the SPOT station were present along the flanks of the sampling grid (light shades in Fig. 3A-C). The communities collected from stations within 2 to $3 \mathrm{~km}$ of the SPOT station (the 8 stations surrounding the SPOT station) had similarity values ranging from 51 to $77 \%$ compared to the 3 replicate communities collected at the SPOT station. Results using the Jaccard index revealed similar heterogeneity among the spatial samples (data not shown).

\section{CLUSTER and nMDS analyses of individual communities}

CLUSTER and nMDS analyses of all spatial (including BR) and daily samples $(\mathrm{n}=465)$ using the $\mathrm{BC}$ index revealed the tendency of communities from the spatial samples to cluster separately from the daily samples (Fig. 4). The CLUSTER analysis of these same samples using the Jaccard index revealed similar clusters, but results of the nMDS are not shown because the stress value of the analysis was high $(0.21)$, indicating it was not a good representation of the community composition variability (Clarke \& Warwick 2001).

CLUSTER and nMDS analyses of the spatial samples (including BR) alone, free from the influence of the daily samples, revealed no consistent clustering pattern for either the BC or Jaccard indices (Fig. 5). The 2 similarity indices produced similar clusters, which often included samples from stations that were adjacent. Some samples from adjacent stations, however, were significantly different to one another (e.g. S14 and S15; SIMPROF; $\mathrm{p}<0.05)$. The sample from the outlying station, BR, clustered consistently with the sample from Stn S8 for both indices, which was the station physically closest to BR $(\sim 6 \mathrm{~km})$.

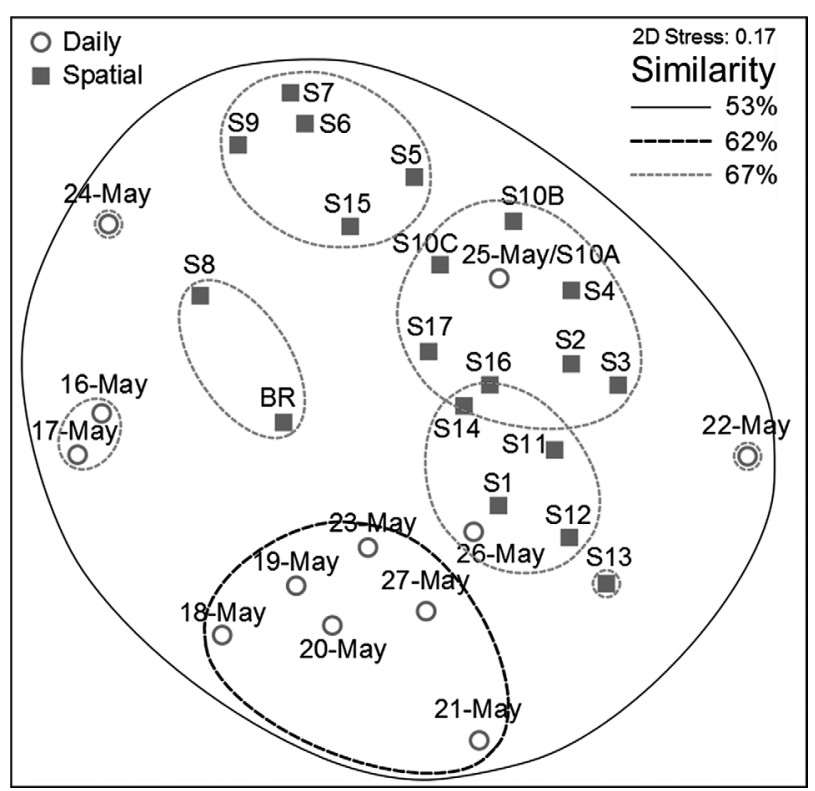

Fig. 4. Non-metric multidimensional scaling (nMDS) analysis using pair-wise Bray-Curtis similarity values estimated for the protistan communities from samples used to examine small-scale spatial and temporal (daily) variability. Group average similarity values of clusters with significant differences from CLUSTER analysis were overlaid on the nMDS plot (SIMPROF; p < 0.05). Communities within the same cluster were not significantly different from each other 

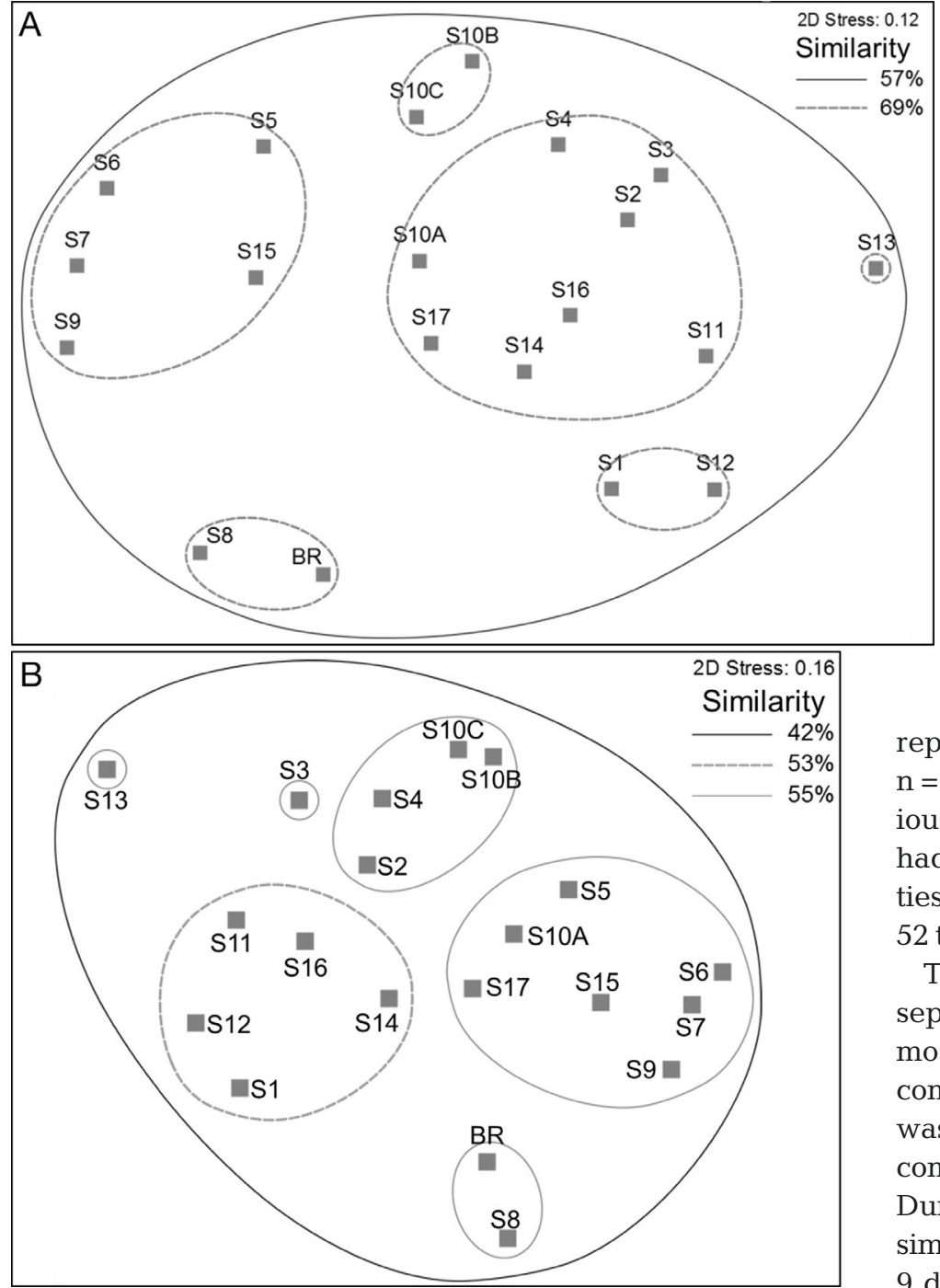

Fig. 5. Non-metric multidimensional scaling (nMDS) analysis using pair-wise (A) Bray-Curtis and (B) Jaccard similarity values estimated for the protistan communities from samples used to examine composition variability over a small spatial scale. Group average similarity values of clusters with significant differences from CLUSTER analysis were overlaid on the nMDS plot (SIMPROF; $\mathrm{p}<0.05$ ). Communities within the same cluster were not significantly different from each other

The 2 similarity indices generated the same clusters for the daily samples (Fig. 6). There were clusters that included samples from consecutive days, but the pattern was not without exceptions (e.g. one cluster contained samples from 22 and 25 May). The trajectory of day-to-day changes in community composition (indicated by lines in Fig. 6) did not exhibit a clear, temporally sequential pattern, indicating that communities did not become progressively more dissimilar over the course of the 12 sampling days. Communities from adjacent days did not necessarily have the highest similarity values, and communities separated by longer periods of time did not necessarily yield the lowest similarity values. Significant differences were observed between some communities from adjacent days (e.g. 17 vs. 18 May; SIMPROF, $\mathrm{p}<0.05)$.

\section{Relationship between community similarities and distance or time separating protistan communities}

There was a weak but significant positive correlation between the similarity values from the spatial samples and distance (RELATE; BC: $\rho=0.303, p=0.006$; Jaccard: $\rho=0.239, p=0.022$ ). Comparison of the average BC similarity of the 3 replicates collected at the SPOT station $(71 \%$; $\mathrm{n}=3$ ) to those of communities separated by various distances apart revealed that the replicates had a higher average similarity than communities separated by 3 to $9 \mathrm{~km}$ (average similarities: 52 to $65 \%$; Dunnett's test; $\mathrm{p}<0.05$; Fig. 7).

The average $\mathrm{BC}$ similarities of communities separated by different number of days were mostly comparable. The average similarity of communities separated by $1 \mathrm{~d}(64 \%, \mathrm{n}=11)$ was only significantly different than that of communities separated by 9 d $(54 \%, n=3$; Dunnett's test; $\mathrm{p}<0.05$; Fig. 8A). The average similarities of communities separated by 1 to 9 d (54 to $64 \%$ ) were significantly lower than the average similarity of the replicate samples (71\%; $\mathrm{n}=3 ; \mathrm{p}<0.05)$, except for communities separated by $7 \mathrm{~d}(61 \%$; $=5 ; \mathrm{p}>0.05)$. Communities separated by these small temporal scales also had significantly lower average similarities compared to communities separated by $2 \mathrm{~km}(67 \%$; $=44 ; \mathrm{p}<0.05)$, except for communities separated by $6(55 \% ; \mathrm{n}=6 ; \mathrm{p}>0.05)$ and $7 \mathrm{~d}(61 \% ; \mathrm{n}=5 ; \mathrm{p}>0.05)$. Spatial variability at the smallest scales (0 to $2 \mathrm{~km}$ apart) was, therefore, generally lower than small-scale temporal variability.

\section{Comparison with a 10 yr T-RFLP dataset collected at the SPOT station}

Results from the present study (spatial and daily samples) were compared to a $10 \mathrm{yr}$ T-RFLP dataset (2000 to 2010; D. Y. Kim et al. unpubl.) investigating 
the community at the SPOT station on a monthly basis (Fig. 8A). Comparison of the average BC similarity values revealed that communities collected 1 to 36 mo apart were significantly lower than averages for communities collected $0 \mathrm{~km}$ (i.e. replicates), $2 \mathrm{~km}$, and $1 \mathrm{~d}$ apart (Dunnet's test; $\mathrm{p}<0.05$ ).

The average $\mathrm{BC}$ similarity value of communities collected during May of different years, an indication of the interannual variability of community composition during May, was $47 \%(\mathrm{n}=8)$, which was the median similarity value among communities collected in various months throughout the $10 \mathrm{yr}$ timeseries ( 39 to $55 \%$; Fig. 8B). The $47 \%$ average BC similarity value of communities collected during May was comparable to the overall average BC similarity value of communities collected 12 mo apart (i.e. overall interannual variability of community composition; $\mathrm{n}=58$; see '12 mo apart' in Fig. 8A).

A CLUSTER analysis was performed using samples from the present study and monthly samples collected from March 2008 to December 2010 to investigate how individual communities in the present study compared to those in samples collected monthly over a period of 3 yr (Fig. 9). Communities collected over small temporal and spatial scales in the present study formed a single cluster within the dataset, indicating that the communities in the present study were more similar to one another than to any community collected at monthly intervals over the 3 yr period.

\section{DISCUSSION}

The present study investigated protistan community composition over small spatial and temporal scales at the SPOT station using T-RFLP. Putative IDs were assigned to OTUs that occurred in more than half the samples to provide taxonomic information for these commonly occurring OTUs. Protistan community compositions were compared using pairwise Bray-Curtis similarity values, and comparisons with a $10 \mathrm{yr}$ T-RFLP dataset from the SPOT station were made.

\section{Commonly occurring taxa in the protistan community}

Putative IDs of the commonly occurring OTUs provided insights into the dominant taxa of the protistan community in the present study. Many of the assigned putative IDs were ciliates and dinoflagellates, and only 3 phytoplankton taxa besides dinoflagellates ( 2 chlorophytes and 1 haptophyte) were among the most common taxa (see Tables S1 \& S2 in the Supplement). Ostreococcus tauri, one of the chlorophytes, occurred in all samples, in agreement with reports that it is commonly
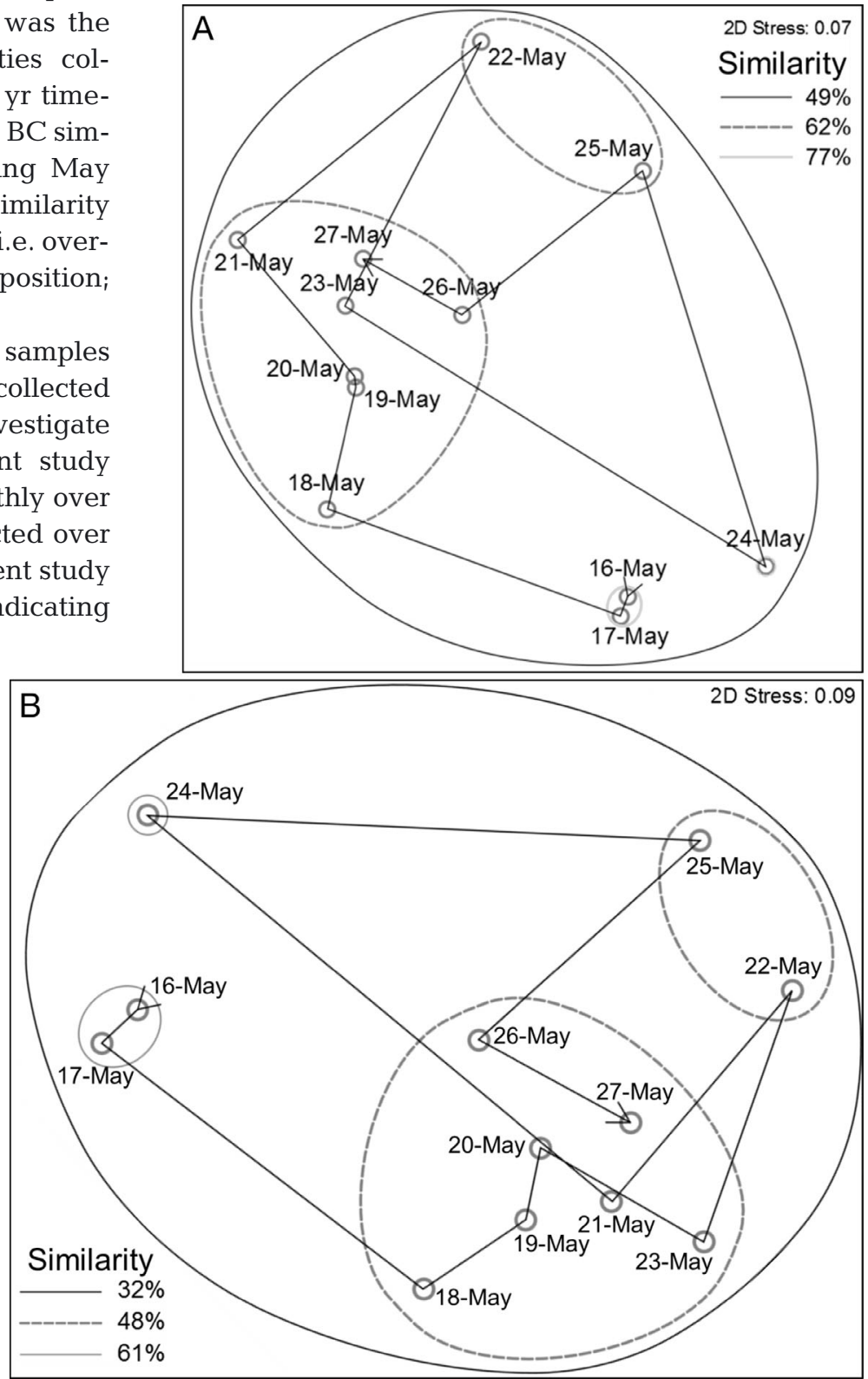

Fig. 6. Non-metric multidimensional scaling (nMDS) analysis using pairwise (A) Bray-Curtis and (B) Jaccard similarity values estimated for the protistan communities from samples collected daily for $12 \mathrm{~d}$. Group average similarity values of clusters with significant differences from CLUSTER analysis were overlaid on the nMDS plot (SIMPROF; $\mathrm{p}<0.05$ ). Communities within the same cluster were not significantly different from each other. Lines between data points connect sampling days sequentially 
present in the surface waters at the SPOT station (Countway \& Caron 2006, Kim et al. 2012). A wide diversity of taxa was observed among the less com-

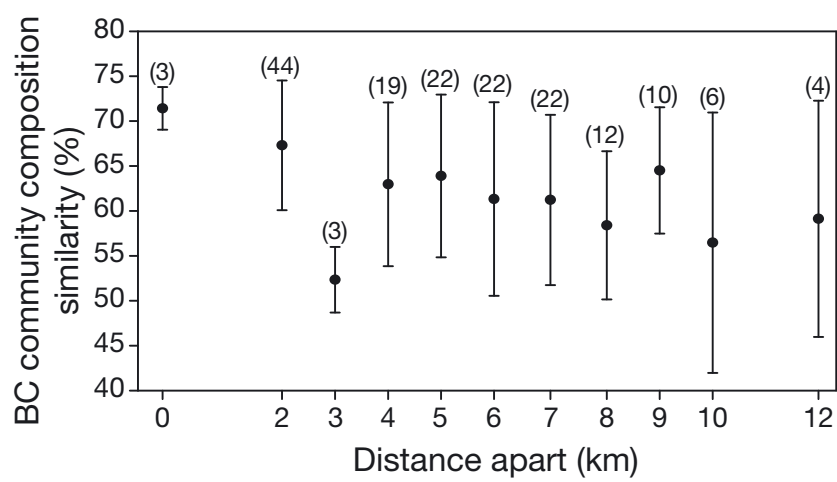

Fig. 7. Average pair-wise Bray-Curtis (BC) similarity values of protistan communities from samples collected different distances apart. Distance between stations was rounded to the nearest kilometer. Numbers in brackets above each data point indicate the number of samples (n). Error bars are standard deviations mon OTUs in the present study (not included in Tables S1 \& S2). Previous studies using cloning and sequencing for the identification of components of the protistan community at the SPOT station have revealed a large number of alveolates and stramenopiles as well as a number of chlorophytes and haptophytes in surface waters (Countway et al. 2010, Schnetzer et al. 2011). D. Y. Kim et al. (unpubl.) used the same reference fragments used in the present study to assign putative IDs to the T-RFLP fragments from the $10 \mathrm{yr}$ dataset collected at the SPOT station, and the method revealed similar groups of protists in their $5 \mathrm{~m}$ samples.

Diatoms are one of the most common groups of phytoplankton in aquatic systems and can be often found in the San Pedro Channel (Schnetzer et al. 2007, Countway et al. 2010). It is therefore surprising that putative IDs assigned to commonly occurring OTUs did not include diatoms in the present study. The only stramenopile among the assigned putative

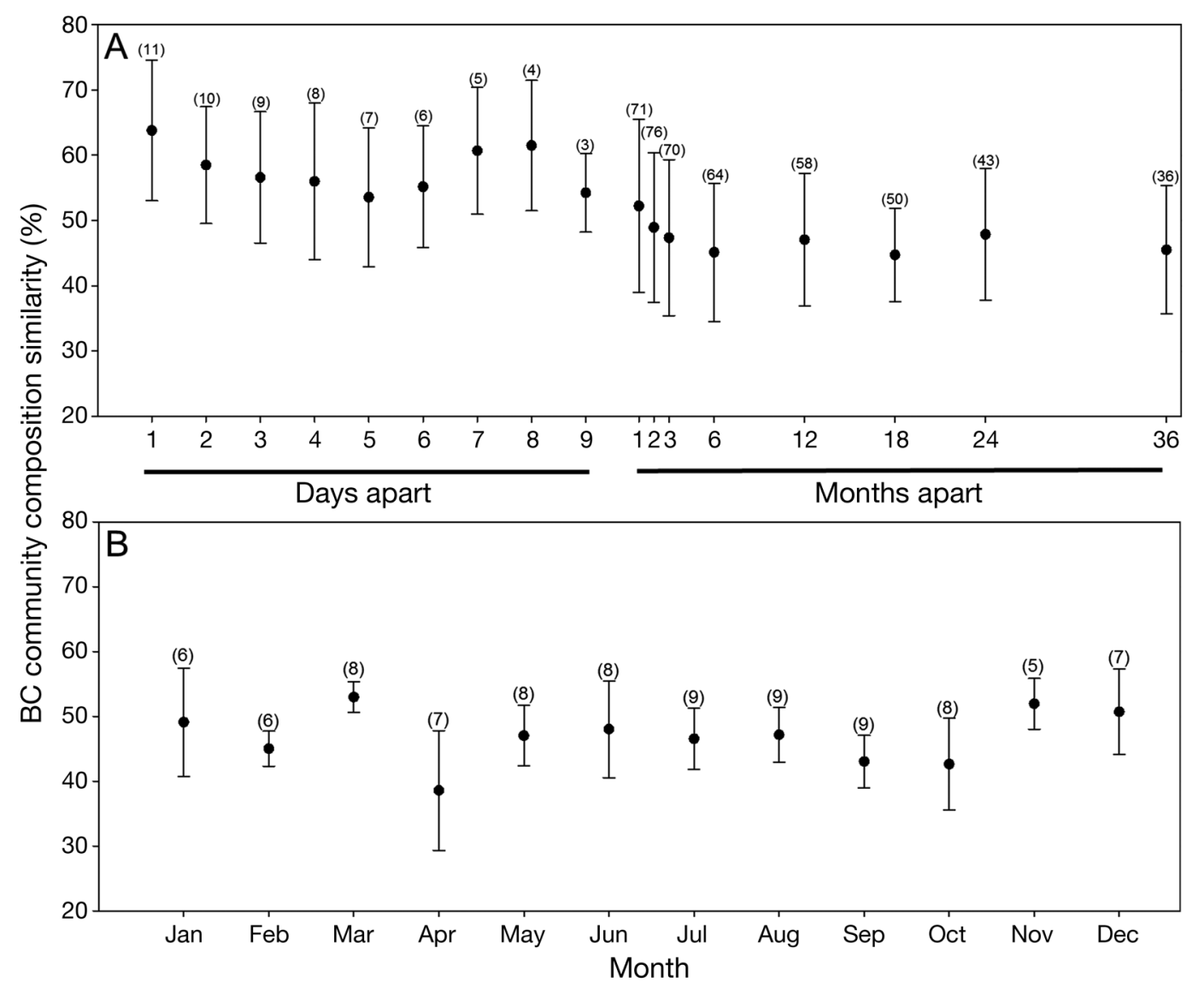

Fig. 8. Variability in protistan community composition over a range of temporal scales. Data points are the average pair-wise Bray-Curtis (BC) similarity values of protistan communities from samples collected (A) different days or months apart and (B) in the same month of different years. Numbers in brackets above each data point indicate the number of samples (n). Error bars are standard deviations. Data of a month or more apart are from a 10 yr T-RFLP dataset (2000-2010) collected monthly at the SPOT station from $5 \mathrm{~m}$ depth (D. Y. Kim et al. unpubl.) 


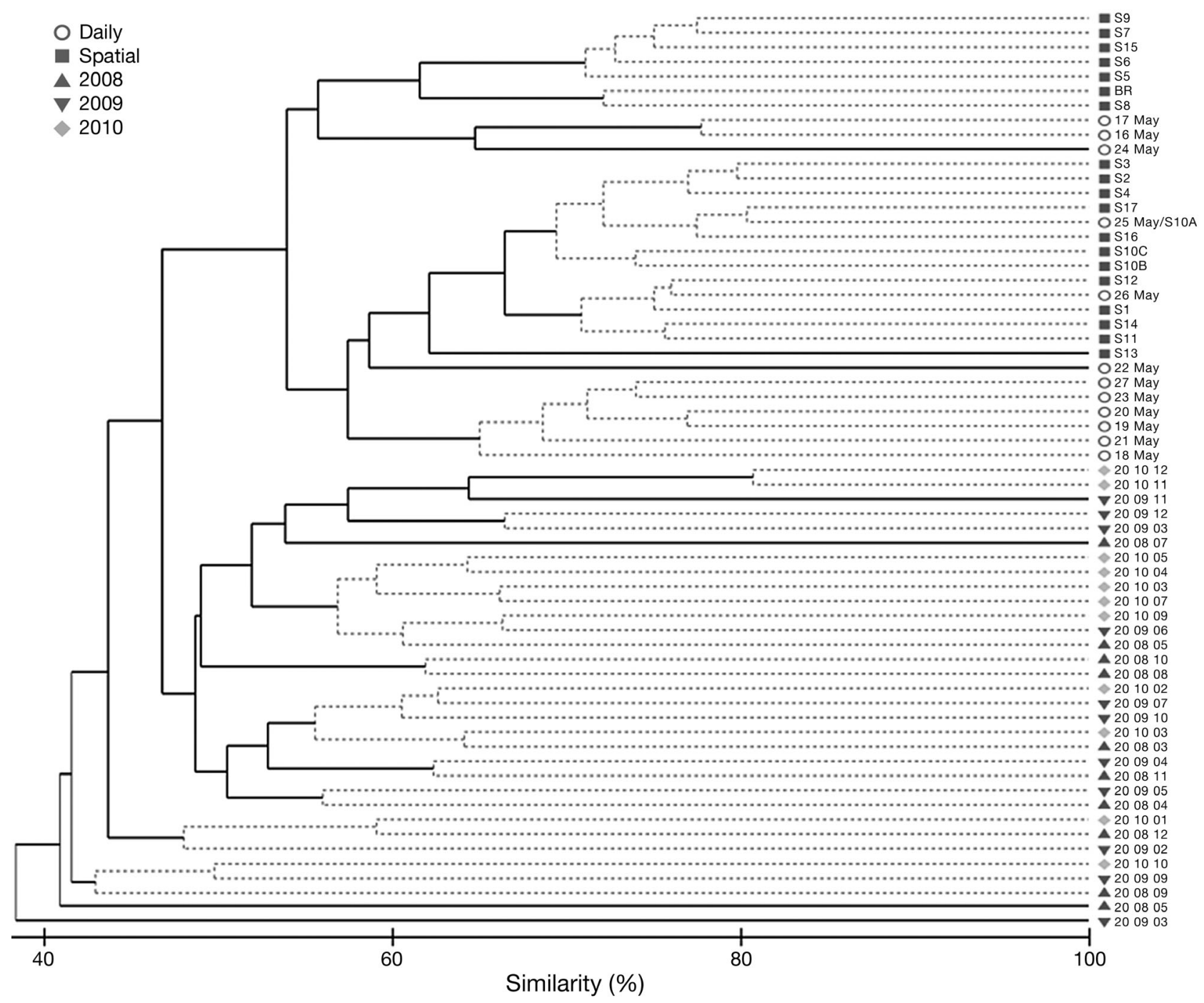

Fig. 9. CLUSTER analysis using pair-wise Bray-Curtis similarity values estimated for protistan communities from samples used to examine small-scale spatial and temporal (daily) variability and from monthly samples collected from March 2008 to December 2010 at the SPOT station. Solid lines indicate significant differences between community compositions (SIMPROF, $\mathrm{p}<0.05)$. Monthly data from 2008 to 2010 were obtained from a 10 yr T-RFLP dataset (2000-2010) collected monthly at the SPOT station from $5 \mathrm{~m}$ depth (D. Y. Kim et al. unpubl.)

IDs was an unspecified stramenopile. Possible reasons explaining the lack of diatoms among the commonly occurring taxa in the present study include technical artifacts (e.g. amplification bias favoring species with high copy numbers of the 18S rRNA gene, such as ciliates and dinoflagellates, see Potvin \& Lovejoy 2009; inefficiency of extracting DNA from diatoms due to their frustules, see Medinger et al. 2010), the lack of taxonomic resolution of the T-RFLP analysis (i.e. same fragment sizes from multiple taxa, see Osborn et al. 2000), or high diversity among diatoms with unique fragment lengths that singly were not high enough for detection by T-RFLP, since only dominant taxa can be detected with this method (Liu et al. 1997).
The reliability of our putative ID assignments was enhanced by the use of full-length sequences obtained from the same locale (Kim et al. 2012), rather than comparing them to large public databases, such as GenBank or SILVA, that contain sequences from various locations and types of environments (Díez et al. 2001a, Fernández-Guerra et al. 2010). Kim et al. (2012) identified OTUs using the same reference fragments for a dataset of monthly samples collected at the SPOT over a period of $3 \mathrm{yr}$. The applicability of this reference dataset for year-round samples is attributed in part to the generally oligotrophic conditions at the SPOT station, which leads to a relatively more stable assemblage of protists (Fuhrman et al. 2006, Kim et al. 2012). 


\section{Variability in protistan community composition over small spatial and temporal scales}

Both sampling and sample-processing variability was reflected in the similarity among the true replicates. T-RFLP has been shown to be a robust and reproducible method (Lukow et al. 2000, Osborn et al. 2000, Dunbar et al. 2001, Rossi et al. 2009), and pseudo-replicates (replicate profiles from the same sample) have been shown to have $<5 \%$ standard deviation in total peak area in a previous study (Vigil et al. 2009) as well as in the present study (data not shown). Variability within replicate samples can be large at times for protistan assemblages. Dolan \& Stoeck (2011) investigated the variability of true replicate samples (10 l) using microscopic counts of tintinnids and reported that the similarity of tintinnid communities in true replicate samples can range from 88 to $96 \%$. Our measures of similarity among true replicates were lower, perhaps in part due to the fact that we sampled the entire protistan community.

Our analysis revealed patches of water with differing protistan assemblages among the 17 closely spaced stations surrounding and including the SPOT station (Fig. 2). This finding is not surprising because it has long been known that the spatial distribution of plankton is patchy at fine (several meters), small (several kilometers), and large (over hundreds of kilometers) scales due to physicochemical and biological processes, such as heterogeneity in resource distribution, turbulent eddies, migration, and differential growth and mortality (Hutchinson 1961, McManus et al. 2003, Cloern \& Dufford 2005, Mitchell et al. 2008, Menden-Deuer \& Fredrickson 2010, Dolan $\&$ Stoeck 2011). The magnitude of the spatial heterogeneity, however, varies greatly among different studies. Menden-Deuer (2008) reported low variability of phytoplankton community composition within a plankton-rich layer (extending up to several kilometers) in a fjord in Washington, USA, while Vigil et al. (2009) found high variability among protistan communities along the east coast of the USA. Vigil et al. (2009) applied the same methodology as the present study, and samples were collected at multiple stations $>10 \mathrm{~km}$ apart. Their results revealed somewhat low community similarities (all similarity values were $<70 \%$, and only $2 \%$ [n $=47$ ] of their pair-wise comparisons between communities collected at different stations on the same day had similarity values of $>60 \%)$. By contrast, $48 \%(\mathrm{n}=31)$ of the pair-wise comparisons of communities collected 10 to $21 \mathrm{~km}$ apart (including comparison to the community from the BR station) on 25 May in our study were $>60 \%$.
The greater community similarities observed in the present study can be explained, in part, by the fact that Vigil et al. (2009) examined a series of estuarine embayments that exhibited distinct chemical or physical conditions.

While the magnitude of small-scale horizontal spatial variability of protistan community composition appears to vary considerably, small-scale vertical spatial variability tends to be high across gradients of environmental parameters. For example, Behnke et al. (2006) noted differences in protistan community composition over a vertical distance of $\sim 30 \mathrm{~m}$ with a steep $\mathrm{O}_{2} / \mathrm{H}_{2} \mathrm{~S}$ gradient. The formation of thin plankton-rich layers at the bases of pycnoclines has been shown to yield community compositions that differed drastically over a few meters (Rines et al. 2002, McManus et al. 2003, Menden-Deuer 2008). Studies of protistan community variability conducted at the SPOT station have also shown high variability between communities found at the surface and those found in deeper layers $(>100 \mathrm{~m})$ due to multiple gradients of environmental factors, including light, temperature, nutrient, and oxygen concentrations (Countway et al. 2010, Schnetzer et al. 2011). The $10 \mathrm{yr}$ T-RFLP dataset collected at the SPOT station revealed that protistan assemblages from within the euphotic zone (5 $\mathrm{m}$ and deep chlorophyll maximum) and below it (150 and $550 \mathrm{~m}$ ) clustered into separate groups regardless of the year or month in which they were collected, indicating that variability of the communities arising from vertical spatial differences overshadowed variability from long-term temporal variations (data not shown; D. Y. Kim et al. unpubl.). Our small-scale data were collected from the water surface, while the long-term data used in the present study (D. Y. Kim et al. unpubl.) were collected from $5 \mathrm{~m}$, but our experience at the SPOT station indicates that the water surface and $5 \mathrm{~m}$ are always within the surface mixed layer (Countway et al. 2010) and are, therefore, comparable.

Significant changes in the protistan communities were observed among some adjacent days during our study of small-scale temporal variability (Fig. 6). The community collected on 24 May, for example, was significantly different than those from 23 May and 25 May (47 to $48 \%$ pair-wise similarity). These changes may reflect either advection of patchy communities or rapid responses of the community to subtle environmental cues. Studies of protistan community composition have reported changes in composition during bottle incubations over 1 or a few days. Countway et al. (2005) and Kim et al. (2011) reported substantial changes in the composition of natural 
protistan communities in containers after $3 \mathrm{~d}$ of incubation even though samples were incubated at ambient light and temperature. Communities perturbed by nutrient enrichments differed dramatically $(<50 \%$ community similarity values) from the original community after only $24 \mathrm{~h}$ of incubation (Kim et al. 2011). A recent study investigating the small-scale temporal variability of the protistan community using pyrosequencing at a lake in France found overall low similarity (average of $34 \%$ ) between communities of small eukaryotes collected 2 to $3 \mathrm{~d}$ apart (Mangot et al. 2013). However, the average similarity among the abundant OTUs ( $>1 \%$ of reads) in their study was $70 \%$, greater than our average BC similarity of $58 \%$ for communities separated by 2 or $3 \mathrm{~d}$. High smallscale temporal variability was also reported by Vigil et al. (2009), who sampled along the east coast of the USA. They observed no similarity values $>70 \%$ for communities collected 5 to $18 \mathrm{~d}$ apart, and only $11 \%$ $(\mathrm{n}=44)$ of these pair-wise comparisons had similarity values $>60 \%$.

Overall, we observed that changes in protistan community composition at small spatial scales (0 to $2 \mathrm{~km}$ apart) were lower than changes over small temporal scales (1 to $9 \mathrm{~d}$ apart). Studies comparing smallscale spatial and temporal variability in protistan community composition are scarce, but MendenDeuer (2008) reported findings similar to ours in her study conducted at East Sound, WA, USA. The author collected samples from 5 stations $<5 \mathrm{~km}$ apart in 2 or $5 \mathrm{~d}$ intervals and observed significant changes in the protistan community composition over time but not between stations on the same day.

\section{Factors affecting protistan community variability over small spatial and temporal scales}

Environmental factors have often been reported as important forces shaping planktonic communities over both spatial and temporal scales (Bark 1981, Lopes et al. 2005, Martiny et al. 2006), but no significant correlations between environmental parameters and small-scale spatial and temporal variability were observed in our study. The lack of correlation between physical and chemical environmental parameters and community similarity in the present study was not surprising given the low variability of these parameters (Tables $1 \& 2$; standard deviation of both spatial and daily measurement of temperature: $0.77^{\circ} \mathrm{C}_{\text {i salinity: }} 0.23 ; \mathrm{pH}: 0.06$ ). Chlorophyll concentrations, on the other hand, correlated with smallscale spatial variability but not temporal variability, most likely due to the fact that chlorophyll concentrations are affected by many factors, including light, nutrient status, and community composition (Geider 1987, Kruskopf \& Flynn 2006), that were more variable over the 12 sampling days than among the 17 closely spaced stations.

Distance within the small-scale sampling grid did not have a major impact on community variability. There was only a weak correlation between distance and spatial variability, and a number of pair-wise comparisons ( $23 \%$ of 171 pair-wise similarity values) between communities separated by up to $14 \mathrm{~km}$ yielded similarity values as high, or even higher, than the average $\mathrm{BC}$ similarity value among the 3 replicate samples collected at the SPOT site $(71 \%)$. At the same time, $10 \%$ of all BC similarity values for communities separated by as little as $3 \mathrm{~km}(\mathrm{n}=171)$ yielded similarity values of $<50 \%$. Results of the Jaccard index also implied a weak correlation between distance and community similarity. Moreover, the average similarity value obtained by comparing the community at the outlying station BR and the communities at the 17 closely spaced stations (BC: $60 \%$; Jaccard: $44 \%$; $\mathrm{n}=$ 19) was comparable to the average similarity value of the communities from the 17 closely spaced stations alone (BC: $63 \%$; Jaccard: $48 \%$; $=171$ ), indicating that communities were, overall, as similar to an outlying station as they were to one another.

Biologically mediated processes, such as differential growth and mortality, presumably contributed to variability in the protistan communities over short temporal or spatial scales. Protists can respond rapidly to biotic and abiotic factors as their high maximal growth rates allow them the potential to increase rapidly in abundance (Crumpton \& Wetzel 1982, Cavender-bares et al. 1999, Arzul et al. 2001, Rose \& Caron 2007). A review of the growth rates of cultured protists by Rose \& Caron (2007) revealed that protists cultured at 16 to $18^{\circ} \mathrm{C}$ had potential growth rates of $1.32 \mathrm{~d}^{-1}$. Rapid shifts in protistan communities detected among some days (e.g. 23, 24, 25 May) in the present study may be a result of differential growth from specific nutritional factors that we did not measure (Hansen 1992, Riebesell et al. 1993, Sunda \& Huntsman 1995, Buskey 1997, Maldonado et al. 1999, Pedersen \& Hansen 2003) or prey selectivity by predators (Bergquist et al. 1985, Elser \& Carpenter 1988). Infections from viruses, bacteria, fungi, and parasitic protists can also lead to rapid changes in their host populations and consequently shifts in the overall community composition (Brussaard 2004, Park et al. 2004, Kagami et al. 2007, Mangot et al. 2010, Sime-Ngando 2012). 
Our study of the small-scale temporal variability of protistan communities was conducted in May, but we are cognizant that variability in community composition may be different in other months. Given that the interannual variability for May was the median of the interannual variability observed for different months (Fig. 8B), and its standard deviation of the interannual variability $(7 \%)$ was on the lower end of the range $(6$ to $14 \%$ ) compared to other months, we speculate that the variability reported in the present study is a reasonable representation of the small-scale temporal variability of protistan communities at the SPOT site.

\section{Comparison of small-scale spatial and temporal variability to monthly, seasonal, and interannual variability}

Small-scale spatial (0 km and $2 \mathrm{~km}$ apart) and dayto-day variability among the protistan communities was significantly lower than monthly variability (Fig. 8A; D. Y. Kim et al. unpubl.), implying that smallscale spatial and temporal differences in sample collection would not obscure information gleaned from the monthly study of protistan communities. This speculation is supported by the observation that communities collected over small spatial or temporal scales in the present study exhibited greater similarity to one another than communities collected monthly from 2008 to 2010 (Fig. 9). The formation of a single cluster comprising all the communities in the present study in the CLUSTER analysis indicates that the variability associated with the communities in the present study was less than the month-to-month variability for the period 2008 to 2010 . Monthly, seasonal, and interannual patterns generated by the monthly samples were, therefore, not masked by the small-scale spatial and daily samples. High monthly variability of protistan communities has also been reported in studies using pyrosequencing (Nolte et al. 2010, Jones et al. in press).

\section{CONCLUSIONS}

The results of the present study provide new insights into protistan community dynamics. Temperature, salinity, $\mathrm{pH}$, wind, and upwelling could not explain the presence of variability among community composition in the present study, and there was only a weak correlation between distance and spatial variability. Variability of true replicates was comparable to communities separated by $2 \mathrm{~km}$, and the variability generated by these small-scale spatial ( 0 to $2 \mathrm{~km}$ ) differences was significantly lower than day-to-day variability of protistan communities. Comparisons with a $10 \mathrm{yr}$ dataset from the same station showed that small-scale spatial (0 to $2 \mathrm{~km})$ and temporal (1 d) community variability was significantly lower than the variability of communities separated by $\geq 1$ mo. Small-scale spatial and temporal variability was, therefore, minor compared to monthly, seasonal, and interannual variability.

Acknowledgements. The authors thank Dr. J. Fuhrman for his advice and suggestions on data analysis, Dr. R. Wilcox for providing statistical advice, and T. Gunderson, V. Campbell, E. Teel, D. Needham, J. Chang, and the crews of the RV 'Yellowfin' and USC 'Miss Christi' for assistance in sample collection. The Wrigley Institute for Environmental Studies provided ship time. This work was funded by NSF grants MCB0703159, MCB-0084231, and OCE-1136818. Summer funding for A.A.Y.L. was provided by the Rose Hills Foundation.

\section{LITERATURE CITED}

Arzul G, Seguel M, Clément A (2001) Effect of marine animal excretions on differential growth of phytoplankton species. ICES J Mar Sci 58:386-390

Bark AW (1981) The temporal and spatial distribution of planktonic and benthic protozoan communities in a small productive lake. Hydrobiologia 85:239-255

Behnke A, Bunge J, Barger K, Breiner HW, Alla V, Stoeck T (2006) Microeukaryote community patterns along an $\mathrm{O}_{2} / \mathrm{H}_{2} \mathrm{~S}$ gradient in a supersulfidic anoxic fjord (Framvaren, Norway). Appl Environ Microbiol 72:3626-3636

- Bergquist AM, Carpenter SR, Latino JC (1985) Shifts in phytoplankton size structure and community composition during grazing by contrasting zooplankton assemblages. Limnol Oceanogr 30:1037-1045

Brussaard CPD (2004) Viral control of phytoplankton population - a review. J Eukaryot Microbiol 51:125-138

> Buskey EJ (1997) Behavioral components of feeding selectivity of the heterotrophic dinoflagellate Protoperidinium pellucidum. Mar Ecol Prog Ser 153:77-89

Caron DA, Countway PD (2009) Hypotheses on the role of the protistan rare biosphere in a changing world. Aquat Microb Ecol 57:227-238

Caron DA, Countway PD, Savai P, Gast RJ and others (2009) Defining DNA-based operational taxonomic units for microbial-eukaryote ecology. Appl Environ Microbiol 75: $5797-5808$

> Caron DA, Countway PD, Jones AC, Kim DY, Schnetzer A (2012) Marine protistan diversity. Annu Rev Mar Sci 4: $467-493$

> Cavender-bares AKK, Mann EL, Chisholm SW, Ondrusek ME, Bidigare RR (1999) Differential response of equatorial Pacific phytoplankton to iron fertilization. Limnol Oceanogr 44:237-246

Clarke KR, Warwick RM (2001) Changes in marine communities: an approach to statistical analysis and interpretation, 2nd edn. PRIMER-E, Plymouth

> Cloern JE, Dufford R (2005) Phytoplankton community ecology: principles applied in San Francisco Bay. Mar Ecol Prog Ser 285:11-28 
Côté B, Platt T (1983) Day-to-day variations in the springsummer photosynthetic parameters of coastal marine phytoplankton. Limnol Oceanogr 28:320-344

Countway PD, Caron DA (2006) Abundance and distribution of Ostreococcus sp. in the San Pedro Channel, California, as revealed by quantitative PCR. Appl Environ Microbiol 72:2496-2506

> Countway PD, Gast RJ, Savai P, Caron DA (2005) Protistan diversity estimates based on 18S rDNA from seawater incubations in the Western North Atlantic. J Eukaryot Microbiol 52:95-106

> Countway PD, Vigil PD, Schnetzer A, Moorthi SD, Caron DA (2010) Seasonal analysis of protistan community structure and diversity at the USC Microbial Observatory (San Pedro Channel, North Pacific Ocean). Limnol Oceanogr 55:2381-2396

> Crumpton WG, Wetzel RG (1982) Effects of differential growth and mortality in the seasonal succession of phytoplankton populations in Lawrence Lake, Michigan. Ecology 63:1729-1739

> Díez B, Pedrós-Alió C, Marsh TL, Massana R (2001a) Application of denaturing gradient gel electrophoresis (DGGE) to study the diversity of marine picoeukaryotic assemblages and comparison of DGGE with other molecular techniques. Appl Environ Microbiol 67:2942-2951

> Díez B, Pedrós-Alió C, Marsh TL, Massana R (2001b) Study of genetic diversity of eukaryotic picoplankton in different oceanic regions by small-subunit rRNA gene cloning and sequencing. Appl Environ Microbiol 67:2932-2941

> Dolan JR, Stoeck T (2011) Repeated sampling reveals differential variability in measures of species richness and community composition in planktonic protists. Environ Microbiol Rep 3:661-666

Dore JE, Letelier RM, Church MJ, Lukas R, Karl DM (2008) Summer phytoplankton blooms in the oligotrophic North Pacific Subtropical Gyre: historical perspective and recent observations. Prog Oceanogr 76:2-38

> Dunbar J, Ticknor LO, Kuske CR (2001) Phylogenetic specificity and reproducibility and new method for analysis of terminal restriction fragment profiles of 16S rRNA genes from bacterial communities. Appl Environ Microbiol 67: 190-197

Egert M, Friedrich MW (2003) Formation of pseudo-terminal restriction fragments, a PCR-related bias affecting terminal restriction fragment length polymorphism analysis of microbial community structure. Appl Environ Microbiol 69:2555-2562

Elser JJ, Carpenter SR (1988) Predation-driven dynamics of zooplankton and phytoplankton communities in a wholelake experiment. Oecologia 76:148-154

> Fernández-Guerra A, Buchan A, Mou X, Casamayor E, Gonzalez J (2010) T-RFPred: a nucleotide sequence size prediction tool for microbial community description based on terminal-restriction fragment length polymorphism chromatograms. BMC Microbiol 10:262

> Fuhrman JA, Hewson I, Schwalbach MS, Steele JA, Brown MV, Naeem S (2006) Annually reoccurring bacterial communities are predictable from ocean conditions. Proc Natl Acad Sci USA 103:13104-13109

> Geider RJ (1987) Light and temperature dependence of the carbon to chlorophyll a ratio in microalgae and cyanobacteria: implications for physiology and growth of phytoplankton. New Phytol 106:1-34

Guillou L, Viprey M, Chambouvet A, Welsh RM and others (2008) Widespread occurrence and genetic diversity of marine parasitoids belonging to Syndiniales (Alveolata). Environ Microbiol 10:3349-3365

- Hansen PJ (1992) Prey size selection, feeding rates and growth dynamics of heterotrophic dinoflagellates with special emphasis on Gyrodinium spirale. Mar Biol 114: 327-334

> Hansen PJ, Koefoed P, Hansen BW (1997) Zooplankton grazing and growth: scaling within the 2-2,000 $\mu \mathrm{m}$ body size range. Limnol Oceanogr 42:687-704

> Hewson I, Steele JA, Capone DG, Fuhrman JA (2006) Temporal and spatial scales of variation in bacterioplankton assemblages of oligotrophic surface waters. Mar Ecol Prog Ser 311:67-77

Hutchinson GE (1961) The paradox of the plankton. Am Nat 95:137-145

Irigoien X, Flynn KJ, Harris RP (2005) Phytoplankton blooms: a 'loophole' in microzooplankton grazing impact? J Plankton Res 27:313-321

Johansson M, Gorokhova E, Larsson U (2004) Annual variability in ciliate community structure, potential prey and predators in the open northern Baltic Sea proper. J Plankton Res 26:67-80

> Jones AC, Liao TSV, Najar FZ, Roe BA, Hambright KD, Caron DA (in press) Seasonality and disturbance: annual pattern and response of the bacterial and microbial eukaryotic assemblages in a freshwater ecosystem. Environ Microbiol

> Kagami M, Bruin A, Ibelings BW, Donk E (2007) Parasitic chytrids: their effects on phytoplankton communities and food-web dynamics. Hydrobiologia 578:113-129

Kim DY, Countway PD, Gast RJ, Caron DA (2011) Rapid shifts in the structure and composition of a protistan assemblage during bottle incubations affect estimates of total protistan species richness. Microb Ecol 62:383-398

Kim DY, Countway PD, Yamashita W, Caron DA (2012) A combined sequence-based and fragment-based characterization of microbial eukaryote assemblages provides taxonomic context for the Terminal Restriction Fragment Length Polymorphism (T-RFLP) method. J Microbiol Methods 91:527-536

> Kruskopf M, Flynn KJ (2006) Chlorophyll content and fluorescence responses cannot be used to gauge reliably phytoplankton biomass, nutrient status or growth rate. New Phytol 169:525-536

> Landry M, Calbet A (2004) Microzooplankton production in the oceans. ICES J Mar Sci 61:501-507

Liu WT, Marsh TL, Cheng H, Forney LJ (1997) Characterization of microbial diversity by determining terminal restriction fragment length polymorphisms of genes encoding 16S rRNA. Appl Environ Microbiol 63: 4516-4522

Long RA, Azam F (2001) Microscale patchiness of bacterioplankton assemblage richness in seawater. Aquat Microb Ecol 26:103-113

> Lopes MRM, de M. Bicudo CE, Ferragut MC (2005) Short term spatial and temporal variation of phytoplankton in a shallow tropical oligotrophic reservoir, southeast Brazil. Hydrobiologia 542:235-247

Lukow T, Dunfield P, Liesack W (2000) Use of the T-RFLP technique to assess spatial and temporal changes in the bacterial community structure within an agricultural soil planted with transgenic and non-transgenic potato plants. FEMS Microbiol Ecol 32:241-247

Maldonado MT, Boyd PW, Harrison PJ, Price NM (1999) Colimitation of phytoplankton growth by light and Fe dur- 
ing winter in the NE subarctic Pacific Ocean. Deep-Sea Res II 46:2475-2485

> Mangot JF, Debroas D, Domaizon I (2010) Perkinsozoa, a well-known marine protozoan flagellate parasite group, newly identified in lacustrine systems: a review. Hydrobiologia 659:37-48

Mangot JF, Domaizon I, Taib N, Marouni N, Duffaud E, Bronner G, Debroas D (2013) Short-term dynamics of diversity patterns: evidence of continual reassembly within lacustrine small eukaryotes. Environ Microbiol 15: 1745-1758

Martiny JBH, Bohannan BJM, Brown JH, Colwell RK and others (2006) Microbial biogeography: putting microorganisms on the map. Nat Rev Microbiol 4:102-112

> McManus MA, Alldredge AL, Barnard AH, Boss E and others (2003) Characteristics, distribution and persistence of thin layers over a 48 hour period. Mar Ecol Prog Ser 261: $1-19$

Medinger R, Nolte V, Pandey RV, Jost S, Ottenwälder B, Schlötterer C, Boenigk J (2010) Diversity in a hidden world: potential and limitation of next-generation sequencing for surveys of molecular diversity of eukaryotic microorganisms. Mol Ecol 19:32-40

Medlin L, Elwood HJ, Stickel S, Sogin ML (1988) The characterization of enzymatically amplified eukaryotic 16Slike rRNA-coding regions. Gene 71:491-499

Menden-Deuer S (2008) Spatial and temporal characteristics of plankton-rich layers in a shallow, temperate fjord. Mar Ecol Prog Ser 355:21-30

Menden-Deuer S, Fredrickson K (2010) Structure-dependent, protistan grazing and its implication for the formation, maintenance and decline of plankton patches. Mar Ecol Prog Ser 420:57-71

Mitchell JG, Yamazaki H, Seuront L, Wolk F, Li H (2008) Phytoplankton patch patterns: seascape anatomy in a turbulent ocean. J Mar Syst 69:247-253

Moreira D, López-García P (2003) Are hydrothermal vents oases for parasitic protists? Trends Parasitol 19:556-558

Nolte V, Pandey RV, Jost S, Medinger R, Ottenwälder B, Boenigk J, Schlötterer C (2010) Contrasting seasonal niche separation between rare and abundant taxa conceals the extent of protist diversity. Mol Ecol 19: 2908-2915

Osborn AM, Moore ER, Timmis KN (2000) An evaluation of terminal-restriction fragment length polymorphism ( $\mathrm{T}$ RFLP) analysis for the study of microbial community structure and dynamics. Environ Microbiol 2:39-50

$>$ Park MG, Yih W, Coats DW (2004) Parasites and phytoplankton, with special emphasis on dinoflagellate infections. J Eukaryot Microbiol 51:145-155

- Pedersen MF, Hansen PJ (2003) Effects of high pH on the growth and survival of six marine heterotrophic protists. Mar Ecol Prog Ser 260:33-41

Potvin M, Lovejoy C (2009) PCR-based diversity estimates of artificial and environmental 18S rRNA gene libraries. J Eukaryot Microbiol 56:174-181

Riebesell U, Wolf-Gladrow DA, Smetacek V (1993) Carbon dioxide limitation of marine phytoplankton growth rates. Nature 361:249-251

Rines JEB, Donaghay PL, Dekshenieks MM, Sullivan JM, Twardowski MS (2002) Thin layers and camouflage: hidden Pseudo-nitzschia spp. (Bacillariophyceae) popula-

Editorial responsibility: Urania Christaki,

Wimereux, France tions in a fjord in the San Juan Islands, Washington, USA. Mar Ecol Prog Ser 225:123-137

Rose JM, Caron DA (2007) Does low temperature constrain the growth rates of heterotrophic protists? Evidence and implications for algal blooms in cold waters. Limnol Oceanogr 52:886-895

> Rossi P, Gillet F, Rohrbach E, Diaby N, Holliger C (2009) Statistical assessment of variability of terminal restriction fragment length polymorphism analysis applied to complex microbial communities. Appl Environ Microbiol 75: 7268-7270

Schnetzer A, Miller PE, Schaffner RA, Stauffer BA and others (2007) Blooms of Pseudo-nitzschia and domoic acid in the San Pedro Channel and Los Angeles harbor areas of the Southern California Bight, 2003-2004. Harmful Algae 6:372-387

> Schnetzer A, Moorthi S, Countway PD, Gast RJ, Gilg IC, Caron DA (2011) Depth matters: microbial eukaryote diversity and community structure in the eastern North Pacific revealed through environmental gene libraries. Deep-Sea Res I 58:16-26

> Seymour JR, Seuront L, Mitchell JG (2005) Microscale and small-scale temporal dynamics of a coastal planktonic microbial community. Mar Ecol Prog Ser 300:21-37

Sherr BF, Sherr EB, Caron DA, Vaulot D, Worden AZ (2007) Oceanic protists. Oceanography (Wash DC) 20:130-134

- Sime-Ngando T (2012) Phytoplankton chytridiomycosis: fungal parasites of phytoplankton and their imprints on the food web dynamics. Front Microbiol 3:361

Steele JA, Countway PD, Xia L, Vigil PD and others (2011) Marine bacterial, archaeal and protistan association networks reveal ecological linkages. ISME J 5:1414-1425

> Steinberg DK, Carlson CA, Bates NR, Johnson RJ, Michaels AF, Knap AH (2001) Overview of the US JGOFS Bermuda Atlantic Time-series Study (BATS): a decadescale look at ocean biology and biogeochemistry. DeepSea Res II 48:1405-1447

Strickland JDH, Parsons TR (1972) A practical handbook of seawater analysis. Fisheries Research Board of Canada, Ottawa

- Sunda WG, Huntsman SA (1995) Iron uptake and growth limitation in oceanic and coastal phytoplankton. Mar Chem 50:189-206

Takao S, Hirawake T, Wright SW, Suzuki K (2012) Variations of net primary productivity and phytoplankton community composition in the Southern Ocean as estimated from ocean-color remote sensing data. Biogeosciences Discuss 9:4361-4398

Vigil P, Countway PD, Rose J, Lonsdale DJ, Gobler CJ, Caron DA (2009) Rapid shifts in dominant taxa among microbial eukaryotes in estuarine ecosystems. Aquat Microb Ecol 54:83-100

> Villareal TA, Brown CG, Brzezinski MA, Krause JW, Wilson C (2012) Summer diatom blooms in the North Pacific subtropical gyre: 2008-2009. PLoS ONE 7:e33109

Wilcox R (2012) Modern statistics for the social and behavioral sciences. CRC Press, Boca Raton, FL

Xu H, Song W, Warren A, Al-Rasheid KAS, Al-Farraj SA, Gong J, Hu X (2008) Planktonic protist communities in a semi-enclosed mariculture pond: structural variation and correlation with environmental conditions. J Mar Biol Assoc UK 88:1353-1362 